\title{
Treatment and prevention of malaria in children
}

Elizabeth A Ashley MB BS ${ }^{1,2}$ and Jeanne Rini Poespoprodjo MD PhD ${ }^{3,4}$

1 Lao-Oxford-Mahosot Hospital-Wellcome Trust Research Unit, Vientiane, Laos

2 Centre for Tropical Medicine and Global Health, Nuffield Department of Medicine, University of Oxford, Oxford, UK

3 Timika Research Facility, Papuan Health and Community Development Foundation, Papua, Indonesia

4 Department of Child Health, Faculty of Medicine, Public Health and Nursing, Universitas Gadjah Mada, Yogyakarta, Indonesia

Corresponding author: Elizabeth A Ashley, Lao-Oxford-Mahosot Hospital-Wellcome Trust Research Unit, Department of Microbiology, Mahosot Hospital, Quai Fa Ngum, Vientiane, Laos; email liz@tropmedres.ac, Tel: +856 21250752

\section{Summary}

Malaria disproportionately affects young children, with falciparum malaria responsible for more than 200000 child deaths each year in Africa, and vivax malaria well-documented as a cause of severe anaemia and excess mortality in children in Asia and the Pacific.

For the treatment of malaria in children, paediatric dosing recommendations for a number of agents, including parenteral artesunate and dihydroartemisinin-piperaquine, have belatedly been shown to be sub-optimal. Worsening antimalarial resistance in the Greater Mekong SubRegion threaten to undermine global malaria control efforts. Triple-antimalarial combination therapies are being evaluated in a bid to head off this threat.

For falciparum malaria prevention, the RTS,S/AS01 vaccine gives partial protection against falciparum malaria and its role as a complementary tool to other treatment and preventive measures is being evaluated in large-scale pilot studies in Ghana, Malawi and Kenya. Seasonal malaria chemoprevention in West Africa has resulted in declines in malaria incidence and deaths and there is interest in scaling up efforts by expanding the age-range of eligible recipients. Prevention of Plasmodium vivax malaria relapse with primaquine remains challenging because of the risk of acute haemolytic anaemia in children with glucose-6-phosphate dehydrogenase (G6PD) deficiency. The safety of adapted escalating dose primaquine regimens is being studied as a way to mitigate this risk.

\section{Keywords}

Malaria, children, treatment, prevention, falciparum, vivax

\section{Background}

More than half of the estimated 405000 deaths from malaria each year are in children below five years of age and are caused by Plasmodium falciparum, with the vast majority taking place on the African continent (Figure 1). ${ }^{1}$ Repeated exposure to malaria leads to gradual acquisition of immunity in those children who survive their infections. ${ }^{2}$ The three countries shouldering the highest burden of falciparum malaria cases are Nigeria (25\%), Democratic Republic of Congo (12\%) and Uganda (5\%). ${ }^{1}$ The two most recent World Malaria Reports have struck a cautionary note, emphasising the slowing down of progress in global malaria control. Recent evidence suggests that P.vivax is endemic throughout Africa, but is 
underreported with the exception of the Horn of Africa and Madagascar. ${ }^{3}$ In the Asia-Pacific region, $P$. vivax is the predominant infection in infants and young children aged less than 5 years old and is recognized as an important cause of morbidity and mortality in malaria endemic areas with multiple Plasmodium species circulating. ${ }^{4,5}$ In Papua (Indonesia) $40-60 \%$ of malaria infections in infancy have been shown to be due to $P$. vivax. ${ }^{6,7}$ Similar findings were described in Papua New Guinea where P.vivax infections were most prevalent in children aged 1-4 years old. ${ }^{8,9}$ P.vivax malaria also predominates in the Americas. Plasmodium ovale (wallikeri and curtisi) infections have a global distribution but most occur in Africa. Plasmodium malariae also occurs in all regions at low incidence. Plasmodium knowlesi malaria is found close to habitats where long-tailed and pig-tailed macaques reside, with the majority of cases reported from Malaysia where it is the leading cause of malaria. ${ }^{10}$

There is uncertainty around the true burden of malaria. The Global Burden of Disease 2017 study estimated malaria mortality to be $\sim 50 \%$ higher than the estimates of the World Health Organization (WHO) for the same year at $618700 .^{3,11}$ There has been good progress in some countries since 2000 with a drop in the total number of countries with endemic malaria from 106 to 86 . The recent Lancet Commission on Malaria Eradication concluded "... that malaria eradication by 2050 is a bold but attainable goal". ${ }^{12}$ This will require substantial investment of an additional two billion dollars per year. At the same time worsening antimalarial drug and insecticide resistance threaten to undermine control and elimination efforts. ${ }^{13}$

This article is the second in a series on treatment and prevention of malaria in children. The first article by Saito et al focuses on pregnancy and the pre-conception period and we review treatment and prevention after birth. ${ }^{14}$

The main clinical presentations of malaria in children are uncomplicated malaria and severe malaria (typically categorized as cerebral malaria or severe malarial anaemia). Congenital malaria (defined as peripheral parasitaemia found in the first 28 days of life) is uncommon but important and the diagnosis may be missed, particularly if the mother is asymptomatic. ${ }^{14}$ Depending on the level of maternal antibody protection, initial non-specific symptoms could be delayed beyond the neonatal period. If they occur in the early neonatal period, they may be confused with neonatal sepsis.

Signs and symptoms of malaria in young children (such as fever, poor feeding, respiratory insufficiency, jaundice and diarrhoea) are similar to those of other systemic infections. ${ }^{7,15}$ For this reason malaria screening of all sick infants and children presenting to healthcare facilities in malaria endemic areas should be carried out. The serious and sometimes fatal consequences of failing to make a prompt diagnosis of malaria are well-described. At the same time overdiagnosis of malaria continues to occur in some settings, usually if healthcare workers rely on clinical assessment. The most challenging patients to diagnose are those who have an incidental peripheral parasitaemia but another cause for their presenting symptoms. ${ }^{16}$

As well as causing avoidable deaths in young children, malaria has other negative impacts on physical and neurocognitive health, with anaemia, impaired school performance and behavioural problems all associated with previous episodes of malaria. ${ }^{17}$ Anaemia is the most prominent adverse health outcome of malaria in children. In Malawi, hospitalized infants with malaria living in high malaria transmission area were twice as likely to have severe anaemia compared to those living in low transmission areas. ${ }^{18}$ The WHO defines severe malarial anaemia in children $<12$ years of age as $\mathrm{Hb}<5 \mathrm{~g} / \mathrm{dL}$, together with a parasite count $>10000 / \mu \mathrm{L}^{19}$ In holoendemic areas in Africa, the risk of malaria-associated severe anaemia is highest in the first 5 years of life and it is associated with an increased risk of dying, particularly for those with $\mathrm{Hb}$ levels below $3 \mathrm{~g} / \mathrm{dL}$. ${ }^{20,21}$ Haemolysis of infected and uninfected red blood cells and bone marrow dyserythropoiesis contribute to the anaemia observed in acute malaria, which 
may be further compounded by inadequate parasite clearance due to ineffective treatment or antimalarial drug resistance and parasite recurrence. ${ }^{20,22,23}$ The majority of descriptions of malarial anaemia relate to falciparum malaria. However, the risk of severe anaemia in Papuan infants with $P$. vivax infections was two fold higher than in those who had $P$. falciparum malaria. ${ }^{7,24}$ Infants and children with $P$. vivax malaria living in tropical endemic areas are at risk of having frequent relapses every 3-7 weeks leaving insufficient time to replace the haemolysed erythrocytes with a resulting severe haematological impact. ${ }^{25,26}$

\section{Asymptomatic infections}

Asymptomatic malaria is well described and is associated with acquisition of immunity which is hardwon during the first five years of life in high transmission areas. Whether it can be regarded as truly asymptomatic is disputed since there is often evidence of inflammation such as platelet and endothelial cell activation. ${ }^{27}$ Asymptomatic (afebrile) infections are more common in $P$. vivax than $P$. falciparum malaria in both high and low malaria transmission areas. ${ }^{28,29} \mathrm{~A}$ household survey carried out in highly malaria endemic areas in Papua (Indonesia) showed that only $5.6 \%$ of children aged less than 5 years old with vivax malaria had a fever compared to $14 \cdot 3 \%$ of those with falciparum malaria. ${ }^{28}$ Similar findings were also observed in the Solomon Islands, an area of low malaria transmission. ${ }^{29}$ In Africa, asymptomatic falciparum malaria infections are associated with the number of infections and the speed of acquisition of immunity to malaria. While asymptomatic infection may occur early in life, it is more common in children aged $>5$ years. ${ }^{30}$

\section{Treatment of malaria in children}

Early detection and prompt effective treatment is central to achieving a good outcome from malaria caused by all species. The objective of vivax malaria treatment is to clear both blood and liver stage infections (radical cure) by using effective schizontocidal and hypnozoitocidal agents (primaquine) to prevent relapse. In low-transmission settings a single-low dose of primaquine is given in addition to schizontocidal therapy for $P$.falciparum infections for its effect on stage $V$ gametocytes. Ivermectin is under evaluation as an alternative transmission blocking agent. ${ }^{31}$ While not recommended for children weighing less than $15 \mathrm{~kg}$, it has been used off-label to treat scabies and other parasitic infestations in this group. More documented evidence of its safety in younger children is needed. Evidence-based guidelines for the treatment of malaria are freely available, published by the $\mathrm{WHO} .^{32}$ It has come to light belatedly that dosing of a number of antimalarials in children is sub-optimal. This is a consequence of designing dosing regimens in a different population (adult) to the one most affected by the disease and has led to revision of some dosing recommendations.

Antimalarial drug doses and regimens for treatment of uncomplicated and severe falciparum and nonfalciparum malaria are summarized in Table 1.

The initial treatment of choice for severe falciparum malaria is clear. Between 2005 and 2010 the AQUAMAT study enrolled 5425 children in nine African countries with an inclusive severe malaria case definition. There was a relative mortality reduction of $22.5 \%(95 \% \mathrm{Cl} 8.1-36.9 ; p=0.0022)$ in artesunatetreated compared to quinine-treated children (Figure 2). Although there has been no clinical trial comparing mortality following intravenous artesunate and quinine for the treatment of severe vivax malaria, the WHO recommends parenteral artesunate (preferably intravenous) as the first line treatment for severe vivax malaria. ${ }^{32}$

Artemisinin-based combination therapy (ACT) has been recommended to treat uncomplicated falciparum malaria since the mid-2000s. More recently ACTs have become the treatment of choice for 
malaria caused by $P$.knowlesi since this parasite has a shorter $24 \mathrm{~h}$ life cycle, and consequent increased risk of high parasite densities and severe disease. ${ }^{33}$ Chloroquine is still the drug of choice for the treatment of chloroquine-sensitive $P$. vivax malaria. The WHO-suggested regimen is a total dose of 25 $\mathrm{mg}$ base/kg given in three divided doses, once daily over 3 days. ACTs can be used for the treatment of $P$. vivax infections, and are recommended in areas where $P$. vivax is highly resistant to chloroquine, such as Indonesia, Colombia (Figure 3). ${ }^{32} 34,35$ In vitro studies have shown that artesunate, lumefantrine, piperaquine and mefloquine are all effective against $P$. vivax. ${ }^{36,37}$ Options for treating uncomplicated malaria caused by P.ovale and P.malariae include chloroquine and ACTs; however treatment efficacy has not been well studied compared to falciparum and vivax malaria and more evidence to define optimal treatment strategies is needed..$^{38-40}$

Long half-life partner drugs in ACTs such as piperaquine (28-35 days) and lumefantrine (about 4 days) delay time to first recurrence (reinfection or relapse). ${ }^{41-43}$ Several efficacy studies have shown that treatment with dihydroartemisinin-piperaquine (DHA-Pip) alone is consistently associated with fewer recurrences at day 42 compared with artemether-lumefantrine $(\mathrm{AL}) \cdot{ }^{44-46} \mathrm{An}$ analysis of reinfection data from treatment studies of uncomplicated malaria in African children estimated that piperaquine and lumefantrine prevent $\geq 90 \%$ reinfections for a mean [range] of $26 \cdot 2$ [13.6 - 45.0] and $12 \cdot 1$ days (range 9.0-20.6 days) respectively. ${ }^{47}$ For Plasmodium vivax malaria treatment, co-administration with primaquine resulted in $92 \%$ reduction of recurrence on day 42 following treatment with DHA-Pip and $80 \%$ reduction of recurrence with $\mathrm{AL}^{46}$

Despite the overwhelming evidence for efficacy and safety of ACTs and parenteral artesunate the reality is that they are still not being used everywhere. ${ }^{48}$ Where they are available they are not always being implemented according to international guidelines. ${ }^{49}$

\section{Pharmacokinetics of antimalarials in children}

Pharmacokinetics (PK) of several antimalarials are different in young children. Artesunate (and its main metabolite dihydroartemisinin) exposure is lower related to larger apparent volume of distribution and faster clearance in children $<25 \mathrm{~kg}$, hence an increased dose of $3 \mathrm{mg} / \mathrm{kg}$ rather than $2.4 \mathrm{mg} / \mathrm{kg}$ is recommended for the treatment of severe malaria. ${ }^{50,51}$ Similarly treatment failure following DHApiperaquine treatment has been found to be higher in young children in a pooled analysis of individual patient data and dosing recommendations have been revised for children in the $<25 \mathrm{~kg}$ weight band. ${ }^{52,53}$ A similar pooled analysis looking at artemether-lumefantrine dosing found that median lumefantrine doses received were lower in children aged 3 to 5 years compared to older children or adults. ${ }^{54}$ Younger children have also been shown to be at higher risk of recrudescent infections. Prolonging the duration of treatment has been proposed to increase treatment efficacy. ${ }^{55} \mathrm{~A}$ population pharmacokinetic nonlinear mixed-effects modelling approach has been used to analyse data from four studies of sulfadoxinepyrimethamine (SP) treatment and concluded that SP bioavailability is lower in underweight children. ${ }^{56}$ There are similar concerns that amodiaquine dosing in children may be too low based on simulations derived from a population PK model. ${ }^{57}$

For the treatment of vivax malaria, sub-therapeutic blood chloroquine concentrations on day 7 have been found in children treated with $25 \mathrm{mg}$ base/ $\mathrm{kg}$ dose with a consequent increased risk of relapse. ${ }^{58,59}$ Increasing the dose to $30 \mathrm{mg}$ base/ $\mathrm{kg}$ in children has been proposed since, in an individual patient metaanalysis, this dose reduced overall recurrence rate by day 42 (adjusted hazard ratio [AHR] 0.82, 95\% Cl $0.69-0.97 ; p=0.021)$ and recurrence rate in children $<5$ years $(0.59,0.41-0.86 ; p=0.0058)$. Adding primaquine treatment further reduced recurrence by $90 \% .{ }^{60}$ Differences in PK of drugs in children may also relate to maturation e.g. of metabolic processes, particularly in the first two years' of life. ${ }^{61}$ Pharmacogenomic factors affecting drug metabolism are under increasing study e.g. CYP2C8 
polymorphisms have been associated with adverse events following amodiaquine treatment. ${ }^{62}$ The efficacy of primaquine to prevent vivax malaria relapse depends on its metabolism by cytochrome P450 2D6. Polymorphisms in CYP2D6 are associated with different primaquine metaboliser phenotypes with resulting differing efficacies for radical cure. ${ }^{63}$

\section{Relapse prevention for vivax malaria-}

$P$. vivax forms hypnozoites that can stay dormant in hepatocytes before causing a malaria relapse at a later date. These liver stage parasites are treated with primaquine (PQ), an 8-aminoquinoline antimalarial drug which may trigger acute hemolysis in G6PD deficient individuals. ${ }^{64-66}$ In tropical regions, $P$. vivax strains can relapse every 3-7 weeks (and are less susceptible to $P Q$ ), whereas in temperate regions hypnozoites may remain dormant for about 9 months (and are more effectively treated with PQ). ${ }^{67,68}$ Infants and young children are at higher risk of frequent relapses associated with lower acquired immunity, and poor treatment adherence, leading to severe anaemia., ${ }^{7,25,69}$ In view of this the WHO recommends use of low dose $(0.25 \mathrm{mg} / \mathrm{kg})$ primaquine for 14 days in infants starting at age 6 months, after G6PD testing, as follow on treatment for malaria caused by P.vivax (and P.ovale). Unfortunately, point of care G6PD testing is not available in the majority of malaria endemic areas and in this situation, the decision to give primaquine must be based on a risk-benefit assessment with close monitoring for primaquine-associated acute intravascular hemolysis. ${ }^{66,70} \mathrm{~A}$ trial is ongoing to assess the safety and tolerability of an escalating dose primaquine regimen in healthy volunteers with G6PD deficiency in Thailand as a possible way to administer primaquine safely in the future without G6PD testing. ${ }^{71}$ This relates to the observation that younger erythrocytes are relatively resistant to oxidant haemolysis so that after an initial moderate drop in haemoglobin following a small dose of primaquine there is a reticulocytosis and repeated primaquine dosing does not lead to severe haemolytic anaemia.

Shortening the duration of primaquine treatment has been proposed to improve adherence. A recent multicentre clinical trial that included infants aged $\geq 6$ months with normal G6PD status, showed that 7 days of high dose primaquine $(1 \mathrm{mg} / \mathrm{kg} /$ day) led to similar rates of symptomatic $P$. vivax infections within the first 12 months as 14 days supervised primaquine $(0.5 \mathrm{mg} / \mathrm{kg} /$ day $)$, with slightly higher rates of gastrointestinal symptoms reported in the 7 day group. ${ }^{72}$

One of the most common complications of falciparum malaria in southeast Asia is a vivax malaria relapse, occurring in almost $30 \%$ of patients by day 63 of follow up. ${ }^{73}$ Multiple infections within a 2 month interval would have a significant haematological and clinical impact on infants and young children. Treatment with long half-life antimalarial drugs is one strategy to delay recurrence, ${ }^{46,73}$ however it has been proposed that applying radical cure treatment for $P$. falciparum malaria might benefit children living in such settings.

\section{Repeated infections and treatment failure-}

In high transmission areas repeated infections are common and associated with early and late mortality. ${ }^{23}$ In addition, a proportion of children will always fail therapy. Reasons for this include poor drug absorption, high parasite densities, non-adherence to therapy and antimalarial drug resistance. Drug resistance is highly likely when repeat malaria episodes occur within 14 days of the primary episode but recrudescence is possible for six to nine weeks and, in the cases of vivax and ovale malaria, relapses may present much later. Repeating the same treatment is a reasonable approach in the event of another episode of malaria unless drug resistance is strongly suspected. ${ }^{74}$ The exception to this is artesunate-mefloquine retreatment, which should not be given more frequently than at two-monthly intervals due to the risk of neurotoxicity. 
There is some evidence that comorbidities may impact on treatment response. Higher numbers of treatment failures were observed in HIV infected adults with $P$. falciparum malaria with CD4 count $<300$ cells/uL following SP and AL. ${ }^{75}$ However, there was no increased risk of malaria treatment failure found in HIV infected children living in malaria endemic area in Uganda. ${ }^{76}$

\section{Dose presentations and delivery-}

Paediatric dosage forms are available for most of the oral fixed-dose combination antimalarials. Most antimalarials are dosed according to body weight. Age-based dosing regimens have been proposed e.g. for artesunate-amodiaquine and single low dose primaquine. ${ }^{77,78}$ To improve access to treatment different models of treatment delivery have been evaluated including community-, school-, and homebased management. ${ }^{79} \mathrm{~A}$ Cochrane systematic review of home- or community-based programmes concluded they improve access to treatment and may reduce mortality from malaria. However the risk of overtreatment when clinical case-definitions of malaria are used was highlighted. ${ }^{80}$ Other formulations of non-injectable antimalarials have been developed over the years to facilitate early treatment of severe malaria in children in remote areas e.g. rectal artesunate and sub-lingual artemether. ${ }^{81}$

\section{Supportive treatment of children with severe malaria-}

Children with severe malaria, are frequently acidotic and anaemic and may be unconscious. ${ }^{19}$ Avoidance of hypoglycemia, treatment of seizures, careful fluid management and judicious blood transfusion are key parts of supportive management. Routine seizure prophylaxis fell out favour after a trial found excess mortality in children with cerebral malaria given phenobarbitone. ${ }^{82}$ The relationship between anaemia and severe malaria is complex. ${ }^{20}$ Findings of a recent retrospective analysis suggest that moderate anaemia may protect against in-hospital mortality in severe falciparum malaria (OR 0.87 for a $10 \%$ decrease in haematocrit [95\% Cl 0.80-0.95]). ${ }^{83}$ Results of the Transfusion and Treatment of Severe Anemia in African Children Trial (TRACT) which included children regardless of malaria status (62\% had malaria) showed no clinical benefit from immediate blood transfusion for all children with uncomplicated severe anaemia compared to the standard approach of transfusing based on clinical severity or a haemoglobin level of less than $4 \mathrm{~g}$ per deciliter, and no advantage to transfusing $30 \mathrm{ml} / \mathrm{kg}$ body weight compared to $20 \mathrm{ml} / \mathrm{kg} .{ }^{84,85}$ Regarding fluid resuscitation in severe malaria, another large study (FEAST) by the same group found excess mortality at 48 hours in severely ill children ( $57 \%$ of whom had malaria) with impaired perfusion (relative risk for any bolus vs. control, $1.45 ; 95 \% \mathrm{Cl}, 1.13$ to 1.86; $\mathrm{P}=0.003) .{ }^{86}$ Concomitant bacterial infection is well-described in children with severe malaria. NonTyphoidal Salmonella bacteraemia is particularly common and empiric antibiotics are often prescribed initially. ${ }^{87}$

\section{Antimalarial drug resistance-}

Loss of antimalarial drug efficacy due to emergence of drug resistance in the parasite has happened repeatedly since the 1950s. Of major concern at present is the emergence and spread of Plasmodium falciparum resistant to artemisinin, piperaquine and mefloquine in the Greater Mekong SubRegion (GMS) (Figure 3). ${ }^{88,89}$ The clinical phenotype of artemisinin resistance is delayed parasite clearance that, in Asia and Latin America, is related to various mutations in the kelch propeller gene on chromosome 13 of the parasite (Table 2). The most well-known mutation is C580Y, which is reaching fixation in some parts of the eastern GMS. The risk of global spread presents a serious threat to child health in subSaharan Africa. Only 20 years ago rising malaria mortality in Africa was associated with increasing chloroquine resistance. ${ }^{90}$ Different strategies under evaluation in Southeast Asia to replace failing 
treatments include extended treatment courses, reintroducing drugs previously lost to resistance and triple antimalarial combinations. ${ }^{91,92}$

Delayed parasite clearance in $P$. vivax infections has not been reported; however it has not been looked for extensively. In Papua (Indonesia), where chloroquine resistance is widespread and ACTs are first line for the treatment of vivax malaria, after nine years of DHA-Pip use (2006 to 2015), P. vivax malaria remains sensitive to DHA-Pip with $100 \%$ of patients parasite free on day 3 in one study. ${ }^{44,93}$

\section{Newer antimalarials}

Newer antimalarial combinations that are ready for use are artesunate-pyronaridine and arterolane maleate-piperaquine. ${ }^{94,95}$ Following signals of hepatotoxicity in earlier trials the safety and efficacy of retreatment with artesunate-pyronaridine was assessed in a sub-study of a large efficacy trial in West African children with reassuring results. ${ }^{96,97}$ In a separate pharmacokinetic study pyronaridine exposure was similar across paediatric weight ranges. ${ }^{98}$ Arterolane maleate is a synthetic trioxolane drug with an elimination half-life of 2-4 hours. In vitro experiments have suggested cross resistance with artemisinin. ${ }^{99}$ This fact, combined with the recent emergence and spread of piperaquine resistance, limits the options for deployment of the combination. Tafenoquine is a long-acting 8-aminoquinoline that has been approved by the European Medicines Agency, US Food and Drug Administration and the Australian Therapeutics Good Administration recently for vivax malaria relapse prevention in adults. There is a lot of interest in this drug which is given as a single-dose, since it could overcome the challenge of adhering to longer courses of primaquine, however, like primaquine, it causes acute haemolytic anaemia in individuals with G6PD deficiency and currently it is not recommended for use in children. An efficacy, safety and pharmacokinetic study in children is due to complete recruitment in 2020 (Trial registration: NCT02563496).

Artefenomel, cipargamin, and ganaplacide are three promising newer antimalarials in clinical development, the latter two being completely unrelated to artemisinin. Experience of their use to treat children is limited. Artefemonel exposure was demonstrated to be lower in children aged between 6 months and 2 years in a pharmacokinetic study, in which the drug was given with piperaquine. ${ }^{100} \mathrm{~A}$ Phase 2 dose-finding safety and efficacy multicentre study (NCT03167242) of ganaplacide combined with lumefantrine solid dispersion formulation is enrolling children 2 to 12 years with uncomplicated falciparum malaria and is due to complete in 2020.

\section{Safety of antimalarials in children-}

The antimalarials in use are generally well-tolerated and safe and have been studied in very large numbers of children. SP treatment is associated with skin reactions or rarely Stevens-Johnson syndrome. When used as prophylaxis in the past, amodiaquine was associated with liver injury and agranulocytosis. ${ }^{101}$ In a systematic review of studies assessing intermittent preventive treatment in children below five years of age no cases of Stevens Johnson syndrome were reported among 32,757 children who received SP and no cases of serious blood dyscrasias or hepatotoxicity were reported among 31,327 children who received amodiaquine. ${ }^{102}$ Mefloquine causes dose-related early vomiting, particularly in young children, In a pooled analysis of 19,850 patients treated with mefloquine, the frequency of early vomiting was $14 \%(106 / 735)$ for children younger than 5 years old, compared to $3 \cdot 8 \%$ $(108 / 2,834)$ in children aged $5-14$ years and $2 \cdot 5 \%(81 / 3,310)$ in older children and adults $(p<0.001) .{ }^{103}$ Post-artesunate delayed haemolytic anaemia has been observed in returned travelers treated for severe malaria but this appears to be an uncommon occurrence in children in endemic areas. ${ }^{104}$ 
There are some important drug-drug interactions between antimalarials and other drug classes such as antiretrovirals and antituberculous therapy (see Table 3).

\section{Prevention}

The negative impacts of malaria infection lead to the unavoidable conclusion that the only acceptable goal is to prevent all episodes of malaria. Ultimately this means eradicating the disease, the feasibility of which has been debated recently. ${ }^{105}$ In the meantime, minimizing the harm caused by malaria in children is achieved through infection prevention with antimalarials, vaccines, insecticide-treated bednets and other vector control interventions.

The two main chemopreventive strategies in endemic countries are seasonal malaria chemoprevention (SMC) and intermittent preventive therapy in infants (IPTi). SMC is recommended for children aged below five years in countries in the Sahel with intense seasonal malaria transmission. A full treatment course of SP+amodiaquine is given monthly up to four times.

SMC has been shown to be highly effective in reducing malaria incidence and there have been calls to expand the target group to older children. ${ }^{106,107}$ In a cluster-randomised trial in Senegal in 2011 that enrolled 2,301 children under 10 years of age in 24 villages, SMC (in addition to community case management) was well-tolerated and associated with 270 malaria cases confirmed by rapid test compared to 1,472 episodes in control villages. ${ }^{106}$ There are different models for delivering SMC such as from a fixed point in the village versus door-to-door versus school-based methods. ${ }^{108}$ Due to concerns that the life-span of SP+amodiaquine will be limited by resistance, DHA-pip has been evaluated as an alternative agent for SMC. Protection from malaria was associated with piperaquine exposure, and results of PK-PD modelling suggest that younger children should receive the revised higher DHA-pip dose given for routine treatment. ${ }^{109-111}$ Using a weekly rather than monthly dosing interval for DHA-pip has also been put forward as a way to maximize protective efficacy. ${ }^{111}$ Mass Drug Administration (MDA) with DHA-pip has also been deployed in some countries as part of a targeted malaria elimination strategy. ${ }^{112}$.

Addition of azithromycin (shown to reduce all-cause mortality in children following mass drug administration for trachoma) to standard SMC was evaluated in a large placebo controlled trial including 19,578 children in Burkina Faso and Mali in 2014. Children who received azithromycin were less likely to go on to experience gastrointestinal infections (incidence rate ratio, $0.85 ; 95 \% \mathrm{Cl}, 0.79$ to 0.91 ) compared to placebo, upper respiratory tract infections (incidence rate ratio, $0.85 ; 95 \% \mathrm{Cl}, 0.81$ to 0.90 ), and non-malarial febrile illnesses (1122 vs. 1424 episodes; incidence rate ratio, $0 \cdot 79 ; 95 \% \mathrm{Cl}, 0 \cdot 73$ to $0 \cdot 87$ ); however there was no difference in incidence of death or hospital admission. ${ }^{113}$

\section{IPTi}

In falciparum malaria-endemic areas with moderate to high transmission, where SMC is not implemented, IPTi with SP is recommended by WHO, provided SP resistance is not established $(<50 \%$ prevalence Pfdhps 540 mutation). IPTi is linked to EPI and given at 10 weeks, 14 weeks and 9 months of age. Despite encouraging results from studies, uptake by countries has been low with Sierra Leone the only country implementing IPTi in $2017 .{ }^{114}$

Delivering IPT to older children in schools has been evaluated in Uganda in a cluster-randomised trial. ${ }^{115}$ Schoolchildren in the 42 clusters allocated to the intervention received monthly DHA-piperaquine for up 
to six rounds. Community-level parasite prevalence estimated during the final survey ( 10 months after the baseline survey) was lower than in the control clusters (19\% vs $23 \%$, adjusted risk ratio $0.85,95 \% \mathrm{Cl}$ $0 \cdot 73-1 \cdot 00, p=0 \cdot 05)$.

Malaria in adolescence is an important health issue with particular implications for young woman of reproductive age. Interventions to treat asymptomatic malaria of any species or latent forms of $P$.vivax pre-conception may reduce the risks of malaria to mother and foetus during pregnancy.

SP should not be given to children with HIV on trimethoprim-sulfamethoxazole prophylaxis. In a randomized controlled trial comparing different chemoprophylactic regimens in young HIV-exposed children in Uganda (subsequently confirmed to be uninfected), DHA-piperaquine showed superior protective efficacy for malaria prevention compared to daily trimethoprim-sulfamethoxazole or monthly SP. ${ }^{116}$ Malaria chemoprevention in children with sickle-cell anaemia is recommended, however there is conflicting evidence regarding benefit in preventing sickle cell crises and associated complications. ${ }^{117,118}$ The risk of malaria rebound in the seasons following mass chemoprophylaxis has been studied in a number of countries with inconsistent results. There is some evidence for an increase in malaria episodes after cessation of prophylaxis in higher transmission areas, however not with more severe outcomes. $^{119-121}$

\section{Prevention of vivax malaria-}

Little information is available on vivax malaria prevention in infants. One study from Papua New Guinea showed that infants are relatively protected from $P$. vivax malaria when given routine intermittent preventive treatment with single dose sulfadoxine-pyrimethamine and 3 day amodiaquine at age 3,6,9 and 12 months old, although the effect was more pronounced in preventing $P$. falciparum infections. ${ }^{122}$

\section{Prevention in travelers-}

If travel to malaria-endemic countries is unavoidable, measures to avoid getting bitten by mosquitoes and chemoprevention with a medicine appropriate to the destination are recommended. Atovaquoneproguanil has been prescribed off licence to children weighing more than $5 \mathrm{~kg}$. Alternatives include weekly mefloquine, although this is associated with higher vomiting rates in young children, ${ }^{123}$ or doxycycline, which is only recommended in children older than 8 years despite the fact that evidence that it causes the same teeth-staining as tetracycline is lacking. ${ }^{124}$ Primaquine is not recommended for prophylaxis in children. Parents and guardians should be warned of signs and symptoms of malaria to look out for and advised to seek testing early. Substandard and falsified antimalarial drugs have been described in many countries. Buying well-known brands may reduce the risk of the former. The best known topical mosquito repellent is $\mathrm{N}, \mathrm{N}$-diethyl-m-toluamide (DEET). DEET is generally considered safe for use in children aged two months and over.

\section{Vaccines-}

RTS,S/AS01 is a pre-erythrocytic vaccine that has been shown to give partial protection against falciparum malaria in a large multicentre trial and has received a favourable opinion from the European Medicines Agency. ${ }^{125}$ The WHO has not recommended its routine introduction into national immunization programmes as yet and three large pilot implementation evaluations are underway in Ghana, Kenya and Malawi that should help to define its use in the future. There are a number of other 
single and multi-stage vaccines in clinical development. ${ }^{126}$ Vaccines against Plasmodium vivax malaria are at a much earlier stage of development with very few human studies to date. ${ }^{127}$

Vector control measures-

Insecticide treated nets (ITNs) have been shown to reduce malaria incidence and child mortality and are a key malaria control intervention. ${ }^{128}$ Increasing pyrethroid resistance in Anopheles mosquitoes is a concern and in response to this pyrethroids have been combined with piperonyl butoxide (PBO) in ITNs, a synergist selected for its inhibitory effect on certain mosquito metabolic enzymes. ${ }^{129}$ In a cluster randomized trial in Tanzania, malaria prevalence assessed by rapid diagnostic tests was lower in children who received $\mathrm{PBO}$ containing nets after nine months compared to those who received ITNs without PBO (531 [29\%] of 1852 children vs 767 [42\%] of 1809; odds ratio [OR] 0.37, 95\% $\mathrm{Cl} 0 \cdot 21-0 \cdot 65 ; \mathrm{p}=0 \cdot 0011$ ). ${ }^{130}$

Indoor residual spraying (IRS) with insecticides is another malaria preventive strategy but household coverage needs to be high ( $\geq 80 \%$ ) to maximize its potential. The duration of protection is approximately three to six months. Results of trials evaluating the impact of adding IRS to ITNs using both pyrethroid and non-pyrethroid insecticides on malaria incidence have been mixed making policy recommendations to national programmes with finite resources difficult. ${ }^{131}$

Research continues on transgenic mosquitoes with the leading approach being genetic engineering and release of sterile male mosquitoes. ${ }^{132}$ Another novel approach to mosquito control that has been piloted in a contained study in Burkina Faso with encouraging results is introduction of transgenic Metarhizium pingshaense carrying toxins that are lethal to mosquitoes. ${ }^{133}$

\section{Conclusion}

The childhood burden of malaria has been high for so long that the annual malaria statistics no longer provoke the outrage and action they deserve. Failure to control malaria will inevitably lead to an increase in the number of child deaths, added to the $>3$ million estimated to have occurred already since 2010. Stagnation of progress to reduce malaria in several countries suggests that action is needed now: increased investment in malaria control efforts using existing tools, continued development of new insecticides, vaccines and drugs for treatment of uncomplicated and severe malaria, as well as new drugs for malaria prevention, including safer agents for vivax malaria relapse prevention (Table 4). Resistance-proofing strategies need to be prioritized at the development stage and in deciding how many and which drugs to incorporate into new combinations. Antimalarial dosing in children ideally needs to be evaluated earlier in the clinical development process to avoid launching new treatments at sub-optimal doses in this vulnerable group.

\section{Acknowledgements}

Thank you to Professor Sir Nicholas J White for providing Figure 2. The Lao-Oxford-Mahosot HospitalWellcome Trust Research Unit is part of the MORU Tropical Health Network funded by the Wellcome Trust. The Timika Research Facility and Papuan Health and Community Development Foundation were supported by AusAID (Australian Agency for International Development, Department of Foreign Affairs and Trade).

\section{Author contributions}

EAA wrote the first draft of the falciparum malaria sections. JRP wrote the first draft of the vivax malaria sections. Both authors reviewed and edited the manuscript before submission. 


\section{Conflicts of interest}

We declare that we have no conflicts of interest Search strategy and selection criteria

We searched PubMed on 22/9/2019 using the terms: (((malaria) AND treatment) AND child) AND ("2014/10/01"[Date - Publication]: "3000"[Date - Publication], and (((malaria) AND prevention) AND child) AND ("2014/10/01"[Date - Publication]: "3000"[Date - Publication]). This identified 3080 references, of which 881 were duplicates. Titles and abstracts of all articles published in English were screened. High quality systematic reviews were prioritised for selection in line with the scope of this review. Additional original references published before 2014 were added from bibliographic searches of these articles and key documents on malaria from the website of the World Health Organization are referenced.

\section{References}

1. World Health Organization. World malaria report 2019. Geneva, Switzerland, 2019.

2. Doolan DL, Dobano C, Baird JK. Acquired immunity to malaria. Clinical microbiology reviews 2009; 22(1): 13-36, Table of Contents.

3. Battle KE, Lucas TCD, Nguyen $M$, et al. Mapping the global endemicity and clinical burden of Plasmodium vivax, 2000-17: a spatial and temporal modelling study. Lancet (London, England) 2019; 394(10195): 332-43.

4. Tjitra E, Anstey NM, Sugiarto $P$, et al. Multidrug-resistant Plasmodium vivax associated with severe and fatal malaria: a prospective study in Papua, Indonesia. PLoS Med 2008; 5(6): e128.

5. Price RN, Tjitra E, Guerra CA, Yeung S, White NJ, Anstey NM. Vivax malaria: neglected and not benign. Am J Trop Med Hyg 2007; 77(6 Suppl): 79-87.

6. Karyana M, Burdarm L, Yeung S, et al. Malaria morbidity in Papua Indonesia, an area with multidrug resistant Plasmodium vivax and Plasmodium falciparum. Malar J 2008; 7: 148.

7. Poespoprodjo JR, Fobia W, Kenangalem E, et al. Vivax malaria: a major cause of morbidity in early infancy. Clin Infect Dis 2009; 48(12): 1704-12.

8. Smith T, Genton B, Baea K, Gibson N, Narara A, Alpers MP. Prospective risk of morbidity in relation to malaria infection in an area of high endemicity of multiple species of Plasmodium. Am J Trop Med Hyg 2001; 64(5-6): 262-7.

9. Genton B, al-Yaman F, Beck HP, et al. The epidemiology of malaria in the Wosera area, East Sepik Province, Papua New Guinea, in preparation for vaccine trials. I. Malariometric indices and immunity. Ann Trop Med Parasitol 1995; 89(4): 359-76.

10. Barber BE, Rajahram GS, Grigg MJ, William T, Anstey NM. World Malaria Report: time to acknowledge Plasmodium knowlesi malaria. Malaria journal 2017; 16(1): 135.

11. Weiss DJ, Lucas TCD, Nguyen M, et al. Mapping the global prevalence, incidence, and mortality of Plasmodium falciparum, 2000-17: a spatial and temporal modelling study. Lancet (London, England) 2019; 394(10195): 322-31.

12. Feachem RGA, Chen I, Akbari O, et al. Malaria eradication within a generation: ambitious, achievable, and necessary. Lancet (London, England) 2019; 394(10203): 1056-112.

13. Ashley EA, Pyae Phyo A, Woodrow CJ. Malaria. Lancet (London, England) 2018; 391(10130): 1608-21.

14. Saito M, XXXX., McGready R. Treatment and prevention of malaria in Pregnancy. Awaiting citation from Lancet $C A H 2020$.

15. Ibhanesebhor SE. Clinical characteristics of neonatal malaria. J Trop Pediatr 1995; 41(6): 330-3.

16. D'Acremont $\mathrm{V}$, Kilowoko $\mathrm{M}$, Kyungu $\mathrm{E}$, et al. Beyond malaria--causes of fever in outpatient

Tanzanian children. The New England journal of medicine 2014; 370(9): 809-17. 
17. Nankabirwa J, Brooker SJ, Clarke SE, et al. Malaria in school-age children in Africa: an increasingly important challenge. Tropical medicine \& international health : TM \& IH 2014; 19(11): 1294309.

18. Slutsker L, Taylor TE, Wirima JJ, Steketee RW. In-hospital morbidity and mortality due to malariaassociated severe anaemia in two areas of Malawi with different patterns of malaria infection. Transactions of the Royal Society of Tropical Medicine and Hygiene 1994; 88(5): 548-51.

19. World Health Organization. Severe malaria. Tropical medicine \& international health : TM \& IH 2014; 19 Suppl 1: 7-131.

20. White NJ. Anaemia and malaria. Malaria journal 2018; 17(1): 371.

21. von Seidlein L, Olaosebikan R, Hendriksen IC, et al. Predicting the clinical outcome of severe falciparum malaria in african children: findings from a large randomized trial. Clinical infectious diseases : an official publication of the Infectious Diseases Society of America 2012; 54(8): 1080-90.

22. Crawley J. Reducing the burden of anemia in infants and young children in malaria-endemic countries of Africa: from evidence to action. The American journal of tropical medicine and hygiene 2004; 71(2 Suppl): 25-34.

23. Patriani $D$, Arguni E, Kenangalem E, et al. Early and late mortality after malaria in young children in Papua, Indonesia. BMC infectious diseases 2019; 19(1): 922.

24. Douglas NM, Lampah DA, Kenangalem E, et al. Major burden of severe anemia from nonfalciparum malaria species in Southern Papua: a hospital-based surveillance study. PLoS Med 2013; 10(12): e1001575; discussion e.

25. White NJ. Determinants of relapse periodicity in Plasmodium vivax malaria. Malar J 2011; 10: 297.

26. Douglas NM, Anstey NM, Buffet PA, et al. The anaemia of Plasmodium vivax malaria. Malar J 2012; 11(1): 135.

27. de Mast $Q$, Brouwers J, Syafruddin $D$, et al. Is asymptomatic malaria really asymptomatic? Hematological, vascular and inflammatory effects of asymptomatic malaria parasitemia. The Journal of infection 2015; 71(5): 587-96.

28. Burdam FH, Hakimi M, Thio F, et al. Asymptomatic Vivax and Falciparum Parasitaemia with Helminth Co-Infection: Major Risk Factors for Anaemia in Early Life. PloS one 2016; 11(8): e0160917. 29. Harris I, Sharrock WW, Bain LM, et al. A large proportion of asymptomatic Plasmodium infections with low and sub-microscopic parasite densities in the low transmission setting of Temotu Province, Solomon Islands: challenges for malaria diagnostics in an elimination setting. Malar J 2010; 9: 254.

30. Cowman AF, Healer J, Marapana D, Marsh K. Malaria: Biology and Disease. Cell 2016; 167(3): 610-24.

31. Alout $\mathrm{H}$, Foy BD. Ivermectin: a complimentary weapon against the spread of malaria? Expert review of anti-infective therapy 2017; 15(3): 231-40.

32. World Health Organization. Guidelines for the treatment of malaria-3rd edition. Geneva, 2015.

33. Barber BE, Grigg MJ, William T, Yeo TW, Anstey NM. The Treatment of Plasmodium knowlesi Malaria. Trends in parasitology 2017; 33(3): 242-53.

34. Price RN, von Seidlein L, Valecha N, Nosten F, Baird JK, White NJ. Global extent of chloroquineresistant Plasmodium vivax: a systematic review and meta-analysis. The Lancet Infectious diseases 2014; 14(10): 982-91.

35. Ratcliff A, Siswantoro $\mathrm{H}$, Kenangalem $\mathrm{E}$, et al. Therapeutic response of multidrug-resistant Plasmodium falciparum and P. vivax to chloroquine and sulfadoxine-pyrimethamine in southern Papua, Indonesia. Trans R Soc Trop Med Hyg 2007; 101(4): 351-9.

36. Chaorattanakawee $\mathrm{S}$, Lon $\mathrm{C}$, Chann $\mathrm{S}$, et al. Measuring ex vivo drug susceptibility in Plasmodium vivax isolates from Cambodia. Malar J 2017; 16(1): 392. 
37. Russell B, Chalfein F, Prasetyorini B, et al. Determinants of in vitro drug susceptibility testing of Plasmodium vivax. Antimicrob Agents Chemother 2008; 52(3): 1040-5.

38. Groger M, Fischer HS, Veletzky L, Lalremruata A, Ramharter M. A systematic review of the clinical presentation, treatment and relapse characteristics of human Plasmodium ovale malaria. Malaria journal 2017; 16(1): 112.

39. Visser BJ, Wieten RW, Kroon D, et al. Efficacy and safety of artemisinin combination therapy (ACT) for non-falciparum malaria: a systematic review. Malaria journal 2014; 13: 463.

40. Groger M, Veletzky L, Lalremruata A, et al. Prospective Clinical Trial Assessing Species-Specific Efficacy of Artemether-Lumefantrine for the Treatment of Plasmodium malariae, Plasmodium ovale, and Mixed Plasmodium Malaria in Gabon. Antimicrobial agents and chemotherapy 2018; 62(3).

41. Ezzet F, van Vugt $M$, Nosten F, Looareesuwan S, White NJ. Pharmacokinetics and pharmacodynamics of lumefantrine (benflumetol) in acute falciparum malaria. Antimicrob Agents Chemother 2000; 44(3): 697-704.

42. Hung TY, Davis TM, Ilett KF, et al. Population pharmacokinetics of piperaquine in adults and children with uncomplicated falciparum or vivax malaria. Br J Clin Pharmacol 2004; 57(3): 253-62.

43. Rodrigo C. How does dihydroartemisinin-piperaquine compare with artemether-lumefantrine in people with uncomplicated falciparum malaria?

44. Ratcliff A, Siswantoro $H$, Kenangalem $E$, et al. Two fixed-dose artemisinin combinations for drugresistant falciparum and vivax malaria in Papua, Indonesia: an open-label randomised comparison. Lancet (London, England) 2007; 369(9563): 757-65.

45. Karunajeewa HA, Mueller I, Senn M, et al. A trial of combination antimalarial therapies in children from Papua New Guinea. N Engl J Med 2008; 359(24): 2545-57.

46. Commons RJ, Simpson JA, Thriemer K, et al. The efficacy of dihydroartemisinin-piperaquine and artemether-lumefantrine with and without primaquine on Plasmodium vivax recurrence: A systematic review and individual patient data meta-analysis. PLoS Med 2019; 16(10): e1002928.

47. Okell LC, Cairns M, Griffin JT, et al. Contrasting benefits of different artemisinin combination therapies as first-line malaria treatments using model-based cost-effectiveness analysis. Nature communications 2014; 5: 5606.

48. Bennett A, Bisanzio D, Yukich JO, et al. Population coverage of artemisinin-based combination treatment in children younger than 5 years with fever and Plasmodium falciparum infection in Africa, 2003-2015: a modelling study using data from national surveys. The Lancet Global health 2017; 5(4): e418-e27.

49. Elnour FA, Alagib MEA, Bansal D, Farag E, Malik EM. Severe malaria management: current situation, challenges and lessons learned from Gezira State, Sudan. Malaria journal 2019; 18(1): 170.

50. Hendriksen IC, Mtove G, Kent A, et al. Population pharmacokinetics of intramuscular artesunate in African children with severe malaria: implications for a practical dosing regimen. Clinical pharmacology and therapeutics 2013; 93(5): 443-50.

51. Zaloumis SG, Tarning J, Krishna S, et al. Population Pharmacokinetics of Intravenous Artesunate: A Pooled Analysis of Individual Data From Patients With Severe Malaria. CPT: pharmacometrics \& systems pharmacology 2014; 3(11): 1-9.

52. The effect of dosing regimens on the antimalarial efficacy of dihydroartemisinin-piperaquine: a pooled analysis of individual patient data. PLoS medicine 2013; 10(12): e1001564; discussion e.

53. Tarning J, Zongo I, Some FA, et al. Population pharmacokinetics and pharmacodynamics of piperaquine in children with uncomplicated falciparum malaria. Clinical pharmacology and therapeutics 2012; 91(3): 497-505.

54. The effect of dose on the antimalarial efficacy of artemether-lumefantrine: a systematic review and pooled analysis of individual patient data. The Lancet Infectious diseases 2015; 15(6): 692-702. 
55. Kloprogge F, Workman L, Borrmann S, et al. Artemether-lumefantrine dosing for malaria treatment in young children and pregnant women: A pharmacokinetic-pharmacodynamic meta-analysis. PLoS medicine 2018; 15(6): e1002579.

56. de Kock M, Tarning J, Workman L, et al. Population Pharmacokinetic Properties of Sulfadoxine and Pyrimethamine: a Pooled Analysis To Inform Optimal Dosing in African Children with Uncomplicated Malaria. Antimicrobial agents and chemotherapy 2018; 62(5).

57. Ali AM, Penny MA, Smith TA, et al. Population Pharmacokinetics of the Antimalarial Amodiaquine: a Pooled Analysis To Optimize Dosing. Antimicrob Agents Chemother 2018; 62(10).

58. Anez A, Moscoso M, Garnica C, Ascaso C. Evaluation of the paediatric dose of chloroquine in the treatment of Plasmodium vivax malaria. Malaria journal 2016; 15(1): 371.

59. Ursing J, Eksborg S, Rombo L, et al. Chloroquine is grossly under dosed in young children with malaria: implications for drug resistance. PLoS One 2014; 9(1): e86801.

60. Commons RJ, Simpson JA, Thriemer K, et al. The effect of chloroquine dose and primaquine on Plasmodium vivax recurrence: a WorldWide Antimalarial Resistance Network systematic review and individual patient pooled meta-analysis. The Lancet Infectious diseases 2018; 18(9): 1025-34.

61. van den Anker J, Reed MD, Allegaert K, Kearns GL. Developmental Changes in Pharmacokinetics and Pharmacodynamics. Journal of clinical pharmacology 2018; 58 Suppl 10: S10-s25.

62. Elewa H, Wilby KJ. A Review of Pharmacogenetics of Antimalarials and Associated Clinical Implications. European journal of drug metabolism and pharmacokinetics 2017; 42(5): 745-56.

63. Bennett JW, Pybus BS, Yadava A, et al. Primaquine failure and cytochrome P-450 2D6 in Plasmodium vivax malaria. The New England journal of medicine 2013; 369(14): 1381-2.

64. John GK, Douglas NM, von Seidlein L, et al. Primaquine radical cure of Plasmodium vivax: a critical review of the literature. Malar J 2012; 11: 280.

65. Cappellini MD, Fiorelli G. Glucose-6-phosphate dehydrogenase deficiency. Lancet 2008; 371(9606): 64-74.

66. Glucose-6-phosphate dehydrogenase deficiency. WHO Working Group. Bull World Health Organ 1989; 67(6): 601-11.

67. Ashley EA, Recht J, White NJ. Primaquine: the risks and the benefits. Malar J 2014; 13: 418.

68. Battle KE, Karhunen MS, Bhatt S, et al. Geographical variation in Plasmodium vivax relapse.

Malar J 2014; 13: 144.

69. Douglas NM, Poespoprodjo JR, Patriani D, et al. Unsupervised primaquine for the treatment of Plasmodium vivax malaria relapses in southern Papua: A hospital-based cohort study. PLoS medicine 2017; 14(8): e1002379.

70. Setyadi A, Arguni E, Kenangalem E, et al. Safety of primaquine in infants with Plasmodium vivax malaria in Papua, Indonesia. Malaria journal 2019; 18(1): 111.

71. Watson J, Taylor WR, Menard D, Kheng S, White NJ. Modelling primaquine-induced haemolysis in G6PD deficiency. eLife 2017; 6.

72. Taylor WRJ, Thriemer K, von Seidlein L, et al. Short-course primaquine for the radical cure of Plasmodium vivax malaria: a multicentre, randomised, placebo-controlled non-inferiority trial. Lancet (London, England) 2019; 394(10202): 929-38.

73. Douglas NM, Nosten F, Ashley EA, et al. Plasmodium vivax recurrence following falciparum and mixed species malaria: risk factors and effect of antimalarial kinetics. Clinical infectious diseases : an official publication of the Infectious Diseases Society of America 2011; 52(5): 612-20.

74. Mavoko HM, Nabasumba C, da Luz RI, et al. Efficacy and safety of re-treatment with the same artemisinin-based combination treatment (ACT) compared with an alternative $A C T$ and quinine plus clindamycin after failure of first-line recommended ACT (QUINACT): a bicentre, open-label, phase 3, randomised controlled trial. The Lancet Global health 2017; 5(1): e60-e8. 
75. Van Geertruyden JP, Mulenga M, Mwananyanda L, et al. HIV-1 immune suppression and antimalarial treatment outcome in Zambian adults with uncomplicated malaria. The Journal of infectious diseases 2006; 194(7): 917-25.

76. Kamya MR, Gasasira AF, Yeka A, et al. Effect of HIV-1 infection on antimalarial treatment outcomes in Uganda: a population-based study. The Journal of infectious diseases 2006; 193(1): 9-15.

77. Taylor W, Terlouw DJ, Olliaro PL, White NJ, Brasseur P, ter Kuile FO. Use of weight-for-age-data to optimize tablet strength and dosing regimens for a new fixed-dose artesunate-amodiaquine combination for treating falciparum malaria. Bulletin of the World Health Organization 2006; 84(12): 956-64.

78. Hayes DJ, van Buuren S, ter Kuile FO, Stasinopoulos DM, Rigby RA, Terlouw DJ. Developing regional weight-for-age growth references for malaria-endemic countries to optimize age-based dosing of antimalarials. Bulletin of the World Health Organization 2015; 93(2): 74-83.

79. Halliday KE, Okello G, Turner EL, et al. Impact of intermittent screening and treatment for malaria among school children in Kenya: a cluster randomised trial. PLoS medicine 2014; 11(1): e1001594.

80. Okwundu Cl, Nagpal S, Musekiwa A, Sinclair D. Home- or community-based programmes for treating malaria. The Cochrane database of systematic reviews 2013; (5): Cd009527.

81. Salman S, Bendel D, Lee TC, Templeton D, Davis TM. Pharmacokinetics of a novel sublingual spray formulation of the antimalarial drug artemether in African children with malaria. Antimicrobial agents and chemotherapy 2015; 59(6): 3208-15.

82. Crawley J, Waruiru C, Mithwani S, et al. Effect of phenobarbital on seizure frequency and mortality in childhood cerebral malaria: a randomised, controlled intervention study. Lancet (London, England) 2000; 355(9205): 701-6.

83. Leopold SJ, Watson JA, Jeeyapant A, et al. Investigating causal pathways in severe falciparum malaria: A pooled retrospective analysis of clinical studies. PLoS medicine 2019; 16(8): e1002858.

84. Maitland K, Olupot-Olupot P, Kiguli S, et al. Transfusion Volume for Children with Severe Anemia in Africa. The New England journal of medicine 2019; 381(5): 420-31.

85. Maitland K, Kiguli S, Olupot-Olupot $\mathrm{P}$, et al. Immediate Transfusion in African Children with Uncomplicated Severe Anemia. The New England journal of medicine 2019; 381(5): 407-19.

86. Maitland K, Kiguli S, Opoka RO, et al. Mortality after fluid bolus in African children with severe infection. The New England journal of medicine 2011; 364(26): 2483-95.

87. Park SE, Pak GD, Aaby P, et al. The Relationship Between Invasive Nontyphoidal Salmonella Disease, Other Bacterial Bloodstream Infections, and Malaria in Sub-Saharan Africa. Clinical infectious diseases : an official publication of the Infectious Diseases Society of America 2016; 62 Suppl 1: S23-31. 88. Woodrow CJ, White NJ. The clinical impact of artemisinin resistance in Southeast Asia and the potential for future spread. FEMS microbiology reviews 2017; 41(1): 34-48.

89. van der Pluijm RW, Imwong M, Chau NH, et al. Determinants of dihydroartemisinin-piperaquine treatment failure in Plasmodium falciparum malaria in Cambodia, Thailand, and Vietnam: a prospective clinical, pharmacological, and genetic study. The Lancet Infectious diseases 2019; 19(9): 952-61.

90. Snow RW, Trape JF, Marsh K. The past, present and future of childhood malaria mortality in Africa. Trends in parasitology 2001; 17(12): 593-7.

91. White NJ. Triple artemisinin-containing combination anti-malarial treatments should be implemented now to delay the emergence of resistance. Malaria journal 2019; 18(1): 338.

92. Krishna S. Triple artemisinin-containing combination anti-malarial treatments should be implemented now to delay the emergence of resistance: the case against. Malaria journal 2019; 18(1): 339. 
93. Poespoprodjo JR, Kenangalem E, Wafom J, et al. Therapeutic Response to DihydroartemisininPiperaquine for P. falciparum and P. vivax Nine Years after Its Introduction in Southern Papua, Indonesia. The American journal of tropical medicine and hygiene 2018; 98(3): 677-82.

94. Pryce J, Hine P. Pyronaridine-artesunate for treating uncomplicated Plasmodium falciparum malaria. The Cochrane database of systematic reviews 2019; 1: Cd006404.

95. Toure OA, Valecha N, Tshefu AK, et al. A Phase 3, Double-Blind, Randomized Study of Arterolane Maleate-Piperaquine Phosphate vs Artemether-Lumefantrine for Falciparum Malaria in Adolescent and Adult Patients in Asia and Africa. Clinical infectious diseases : an official publication of the Infectious Diseases Society of America 2016; 62(8): 964-71.

96. Sagara I, Beavogui AH, Zongo I, et al. Safety and efficacy of re-treatments with pyronaridineartesunate in African patients with malaria: a substudy of the WANECAM randomised trial. The Lancet Infectious diseases 2016; 16(2): 189-98.

97. Pyronaridine-artesunate or dihydroartemisinin-piperaquine versus current first-line therapies for repeated treatment of uncomplicated malaria: a randomised, multicentre, open-label, longitudinal, controlled, phase 3b/4 trial. Lancet (London, England) 2018; 391(10128): 1378-90.

98. Ayyoub A, Methaneethorn J, Ramharter M, et al. Population Pharmacokinetics of Pyronaridine in Pediatric Malaria Patients. Antimicrobial agents and chemotherapy 2015; 60(3): 1450-8.

99. Straimer J, Gnadig NF, Stokes BH, Ehrenberger M, Crane AA, Fidock DA. Plasmodium falciparum K13 Mutations Differentially Impact Ozonide Susceptibility and Parasite Fitness In Vitro. mBio 2017; 8(2). 100. Macintyre $F$, Adoke $Y$, Tiono AB, et al. A randomised, double-blind clinical phase II trial of the efficacy, safety, tolerability and pharmacokinetics of a single dose combination treatment with artefenomel and piperaquine in adults and children with uncomplicated Plasmodium falciparum malaria. BMC medicine 2017; 15(1): 181.

101. Neftel KA, Woodtly W, Schmid M, Frick PG, Fehr J. Amodiaquine induced agranulocytosis and liver damage. Br Med J (Clin Res Ed) 1986; 292(6522): 721-3.

102. Wilson AL. A systematic review and meta-analysis of the efficacy and safety of intermittent preventive treatment of malaria in children (IPTC). PloS one 2011; 6(2): e16976.

103. Lee SJ, Ter Kuile FO, Price RN, Luxemburger C, Nosten F. Adverse effects of mefloquine for the treatment of uncomplicated malaria in Thailand: A pooled analysis of 19,850 individual patients. PloS one 2017; 12(2): e0168780.

104. Fanello C, Onyamboko M, Lee SJ, et al. Post-treatment haemolysis in African children with hyperparasitaemic falciparum malaria; a randomized comparison of artesunate and quinine. BMC infectious diseases 2017; 17(1): 575.

105. World Health Organization. Malaria eradication: benefits, future scenarios and feasibility. Executive summary, WHO Strategic Advisory Group on Malaria Eradication, 2019.

106. Ndiaye JLA, Ndiaye $\mathrm{Y}, \mathrm{Ba}$ MS, et al. Seasonal malaria chemoprevention combined with community case management of malaria in children under 10 years of age, over 5 months, in south-east Senegal: A cluster-randomised trial. PLoS medicine 2019; 16(3): e1002762.

107. Cisse B, Ba EH, Sokhna C, et al. Effectiveness of Seasonal Malaria Chemoprevention in Children under Ten Years of Age in Senegal: A Stepped-Wedge Cluster-Randomised Trial. PLoS medicine 2016; 13(11): e1002175.

108. Barry A, Issiaka D, Traore $\mathrm{T}$, et al. Optimal mode for delivery of seasonal malaria chemoprevention in Ouelessebougou, Mali: A cluster randomized trial. PloS one 2018; 13(3): e0193296. 109. Zongo I, Milligan P, Compaore YD, et al. Randomized Noninferiority Trial of DihydroartemisininPiperaquine Compared with Sulfadoxine-Pyrimethamine plus Amodiaquine for Seasonal Malaria Chemoprevention in Burkina Faso. Antimicrobial agents and chemotherapy 2015; 59(8): 4387-96. 
110. Sundell K, Jagannathan $\mathrm{P}$, Huang $\mathrm{L}$, et al. Variable piperaquine exposure significantly impacts protective efficacy of monthly dihydroartemisinin-piperaquine for the prevention of malaria in Ugandan children. Malaria journal 2015; 14: 368.

111. Chotsiri P, Zongo I, Milligan $\mathrm{P}$, et al. Optimal dosing of dihydroartemisinin-piperaquine for seasonal malaria chemoprevention in young children. Nature communications 2019; 10(1): 480.

112. von Seidlein L, Peto TJ, Landier J, et al. The impact of targeted malaria elimination with mass drug administrations on falciparum malaria in Southeast Asia: A cluster randomised trial. PLoS medicine 2019; 16(2): e1002745.

113. Chandramohan D, Dicko A, Zongo I, et al. Effect of Adding Azithromycin to Seasonal Malaria Chemoprevention. The New England journal of medicine 2019; 380(23): 2197-206.

114. World Health Organization. Malaria Prevention Works: let's close the gap, 2017.

115. Staedke SG, Maiteki-Sebuguzi C, Rehman AM, et al. Assessment of community-level effects of intermittent preventive treatment for malaria in schoolchildren in Jinja, Uganda (START-IPT trial): a cluster-randomised trial. The Lancet Global health 2018; 6(6): e668-e79.

116. Kamya MR, Kapisi J, Bigira V, et al. Efficacy and safety of three regimens for the prevention of malaria in young HIV-exposed Ugandan children: a randomized controlled trial. AIDS (London, England) 2014; 28(18): 2701-9.

117. Oniyangi O, Omari AA. Malaria chemoprophylaxis in sickle cell disease. The Cochrane database of systematic reviews 2019; 2019(11).

118. Frimpong A, Thiam LG, Arko-Boham B, Owusu EDA, Adjei GO. Safety and effectiveness of antimalarial therapy in sickle cell disease: a systematic review and network meta-analysis. $B M C$ infectious diseases 2018; 18(1): 650.

119. Portugal S, Tran TM, Ongoiba A, et al. Treatment of Chronic Asymptomatic Plasmodium falciparum Infection Does Not Increase the Risk of Clinical Malaria Upon Reinfection. Clinical infectious diseases : an official publication of the Infectious Diseases Society of America 2017; 64(5): 645-53.

120. Greenwood BM, David PH, Otoo-Forbes LN, et al. Mortality and morbidity from malaria after stopping malaria chemoprophylaxis. Transactions of the Royal Society of Tropical Medicine and Hygiene 1995; 89(6): 629-33.

121. Muhindo MK, Jagannathan $\mathrm{P}$, Kakuru A, et al. Intermittent preventive treatment with dihydroartemisinin-piperaquine and risk of malaria following cessation in young Ugandan children: a double-blind, randomised, controlled trial. The Lancet Infectious diseases 2019; 19(9): 962-72.

122. Senn N, Rarau P, Stanisic DI, et al. Intermittent preventive treatment for malaria in Papua New Guinean infants exposed to Plasmodium falciparum and P. vivax: a randomized controlled trial. PLoS Med 2012; 9(3): e1001195.

123. Luxemburger C, Price RN, Nosten F, Ter Kuile FO, Chongsuphajaisiddhi T, White NJ. Mefloquine in infants and young children. Annals of tropical paediatrics 1996; 16(4): 281-6.

124. Poyhonen $\mathrm{H}$, Nurmi M, Peltola V, Alaluusua S, Ruuskanen O, Lahdesmaki T. Dental staining after doxycycline use in children. The Journal of antimicrobial chemotherapy 2017; 72(10): 2887-90.

125. Efficacy and safety of RTS,S/AS01 malaria vaccine with or without a booster dose in infants and children in Africa: final results of a phase 3, individually randomised, controlled trial. Lancet (London, England) 2015; 386(9988): 31-45.

126. World Health Organization. Tables of malaria vaccine projects globally: "The Rainbow Tables". 2017. https://www.who.int/immunization/research/development/Rainbow_tables/en/ (accessed 26th October 2019).

127. Tham WH, Beeson JG, Rayner JC. Plasmodium vivax vaccine research - we've only just begun. International journal for parasitology 2017; 47(2-3): 111-8.

128. Pryce J, Richardson M, Lengeler C. Insecticide-treated nets for preventing malaria. The Cochrane database of systematic reviews 2018; 11: Cd000363. 
129. Gleave K, Lissenden N, Richardson M, Choi L, Ranson H. Piperonyl butoxide (PBO) combined with pyrethroids in insecticide-treated nets to prevent malaria in Africa. The Cochrane database of systematic reviews 2018; 11: Cd012776.

130. Protopopoff N, Mosha JF, Lukole E, et al. Effectiveness of a long-lasting piperonyl butoxidetreated insecticidal net and indoor residual spray interventions, separately and together, against malaria transmitted by pyrethroid-resistant mosquitoes: a cluster, randomised controlled, two-by-two factorial design trial. Lancet (London, England) 2018; 391(10130): 1577-88.

131. Choi L, Pryce J, Garner P. Indoor residual spraying for preventing malaria in communities using insecticide-treated nets. The Cochrane database of systematic reviews 2019; 5: Cd012688.

132. Bernardini F, Haghighat-Khah RE, Galizi R, Hammond AM, Nolan T, Crisanti A. Molecular tools and genetic markers for the generation of transgenic sexing strains in Anopheline mosquitoes. Parasites \& vectors 2018; 11(Suppl 2): 660.

133. Lovett $B$, Bilgo E, Millogo SA, et al. Transgenic Metarhizium rapidly kills mosquitoes in a malariaendemic region of Burkina Faso. Science (New York, NY) 2019; 364(6443): 894-7.

134. Dondorp AM, Fanello $\mathrm{Cl}$, Hendriksen IC, et al. Artesunate versus quinine in the treatment of severe falciparum malaria in African children (AQUAMAT): an open-label, randomised trial. Lancet (London, England) 2010; 376(9753): 1647-57.

135. Zani B, Gathu M, Donegan S, Olliaro PL, Sinclair D. Dihydroartemisinin-piperaquine for treating uncomplicated Plasmodium falciparum malaria. The Cochrane database of systematic reviews 2014; (1): Cd010927.

136. Gargano N, Madrid L, Valentini G, et al. Efficacy and Tolerability Outcomes of a Phase II, Randomized, Open-Label, Multicenter Study of a New Water-Dispersible Pediatric Formulation of Dihydroartemisinin-Piperaquine for the Treatment of Uncomplicated Plasmodium falciparum Malaria in African Infants. Antimicrobial agents and chemotherapy 2018; 62(1).

137. Sirima SB, Ogutu B, Lusingu JPA, et al. Comparison of artesunate-mefloquine and artemetherlumefantrine fixed-dose combinations for treatment of uncomplicated Plasmodium falciparum malaria in children younger than 5 years in sub-Saharan Africa: a randomised, multicentre, phase 4 trial. The Lancet Infectious diseases 2016; 16(10): 1123-33.

138. Adjuik MA, Allan R, Anvikar AR, et al. The effect of dosing strategies on the therapeutic efficacy of artesunate-amodiaquine for uncomplicated malaria: a meta-analysis of individual patient data. $B M C$ medicine 2015; 13: 66.

139. Adam I, Ibrahim Y, Gasim Gl. Efficacy and safety of artemisinin-based combination therapy for uncomplicated Plasmodium falciparum malaria in Sudan: a systematic review and meta-analysis. Malaria journal 2018; 17(1): 110.

140. Goncalves BP, Tiono AB, Ouedraogo A, et al. Single low dose primaquine to reduce gametocyte carriage and Plasmodium falciparum transmission after artemether-lumefantrine in children with asymptomatic infection: a randomised, double-blind, placebo-controlled trial. BMC medicine 2016; 14: 40.

141. Nguyen TH, Day NP, Ly VC, et al. Post-malaria neurological syndrome. Lancet (London, England) 1996; 348(9032): 917-21.

142. German P, Greenhouse B, Coates C, et al. Hepatotoxicity due to a drug interaction between amodiaquine plus artesunate and efavirenz. Clinical infectious diseases : an official publication of the Infectious Diseases Society of America 2007; 44(6): 889-91.

143. Hoglund RM, Byakika-Kibwika P, Lamorde M, et al. Artemether-lumefantrine co-administration with antiretrovirals: population pharmacokinetics and dosing implications. British journal of clinical pharmacology 2015; 79(4): 636-49. 
144. Byakika-Kibwika P, Lamorde M, Mayito J, et al. Significant pharmacokinetic interactions between artemether/lumefantrine and efavirenz or nevirapine in HIV-infected Ugandan adults. The Journal of antimicrobial chemotherapy 2012; 67(9): 2213-21.

145. Zakaria Z, Badhan RKS. The impact of CYP2B6 polymorphisms on the interactions of efavirenz with lumefantrine: Implications for paediatric antimalarial therapy. European journal of pharmaceutical sciences : official journal of the European Federation for Pharmaceutical Sciences 2018; 119: 90-101.

146. German P, Parikh S, Lawrence J, et al. Lopinavir/ritonavir affects pharmacokinetic exposure of artemether/lumefantrine in HIV-uninfected healthy volunteers. Journal of acquired immune deficiency syndromes (1999) 2009; 51(4): 424-9.

147. Kakuda TN, DeMasi R, van Delft Y, Mohammed P. Pharmacokinetic interaction between etravirine or darunavir/ritonavir and artemether/lumefantrine in healthy volunteers: a two-panel, twoway, two-period, randomized trial. HIV medicine 2013; 14(7): 421-9.

148. Lefevre G, Bindschedler M, Ezzet F, Schaeffer N, Meyer I, Thomsen MS. Pharmacokinetic interaction trial between co-artemether and mefloquine. European journal of pharmaceutical sciences : official journal of the European Federation for Pharmaceutical Sciences 2000; 10(2): 141-51.

149. van Luin $\mathrm{M}$, Van der Ende ME, Richter C, et al. Lower atovaquone/proguanil concentrations in patients taking efavirenz, lopinavir/ritonavir or atazanavir/ritonavir. AIDS (London, England) 2010; 24(8): 1223-6.

150. Hanboonkunupakarn B, Ashley EA, Jittamala P, et al. Open-label crossover study of primaquine and dihydroartemisinin-piperaquine pharmacokinetics in healthy adult thai subjects. Antimicrobial agents and chemotherapy 2014; 58(12): 7340-6.

151. Jittamala P, Pukrittayakamee S, Ashley EA, et al. Pharmacokinetic interactions between primaquine and pyronaridine-artesunate in healthy adult Thai subjects. Antimicrobial agents and chemotherapy 2015; 59(1): 505-13.

152. Pukrittayakamee S, Tarning J, Jittamala P, et al. Pharmacokinetic interactions between primaquine and chloroquine. Antimicrobial agents and chemotherapy 2014; 58(6): 3354-9.

153. Leroy D, Macintyre F, Adoke $Y$, et al. African isolates show a high proportion of multiple copies of the Plasmodium falciparum plasmepsin-2 gene, a piperaquine resistance marker. Malaria journal 2019; 18(1): 126.

Key-points

- Most malaria-related deaths are in children

- Paediatric dosing regimens for several antimalarials have been found to be sub-optimal post registration

- Resistance to most of the antimalarials in use is increasing, particularly in southeast Asia

- Uptake of radical curative treatments for vivax malaria in children is low related to safety concerns with administering 8-aminoquinolines without G6PD testing

- Seasonal malaria chemoprevention is effective at preventing malaria episodes in the Sahel 


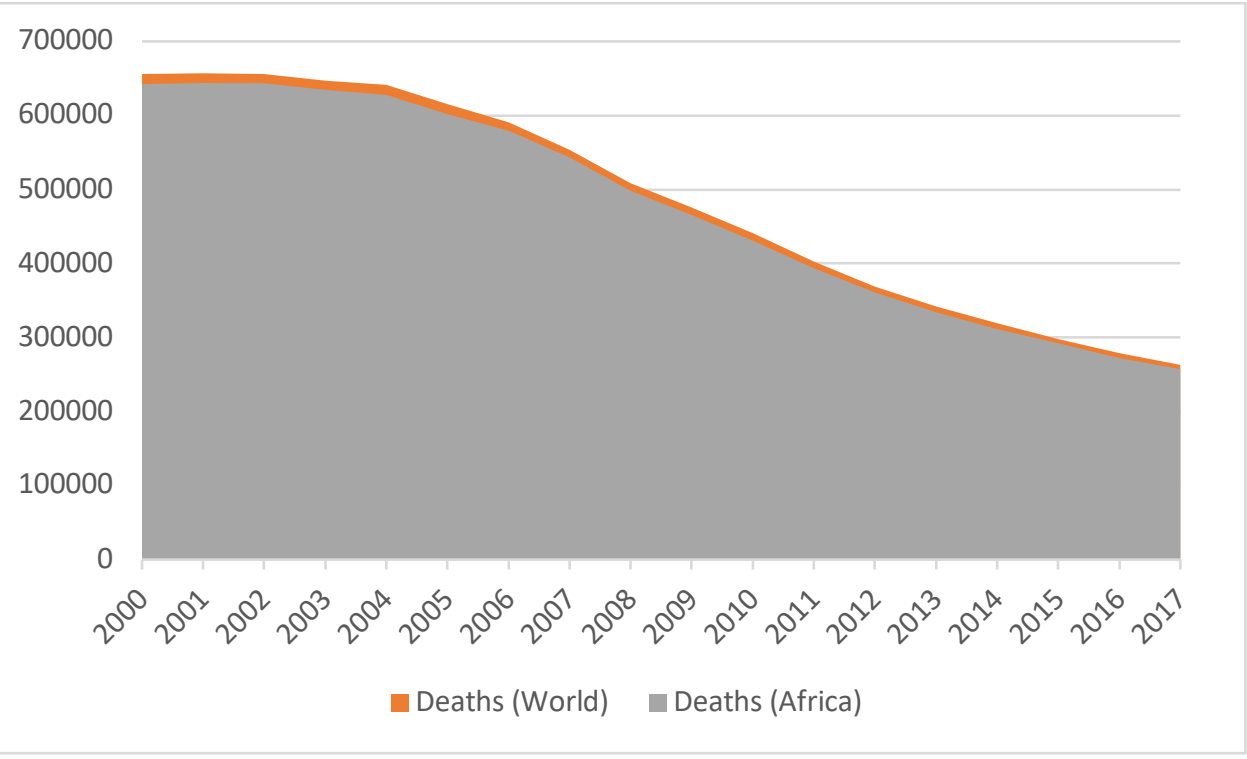

Figure 1 Estimated deaths from malaria in children aged 1-59 months, 2000-2017

\section{Footnote}

Figure shows the trend in estimated under 5 malaria mortality since 2000 . An estimated 8.7 million children aged 1-59 months died of malaria between 2000 and 2017, of whom 98\% were in the African region (WHO Global Health Observatory 2019).

$y$ axis Number of deaths

$x$ axis Year 


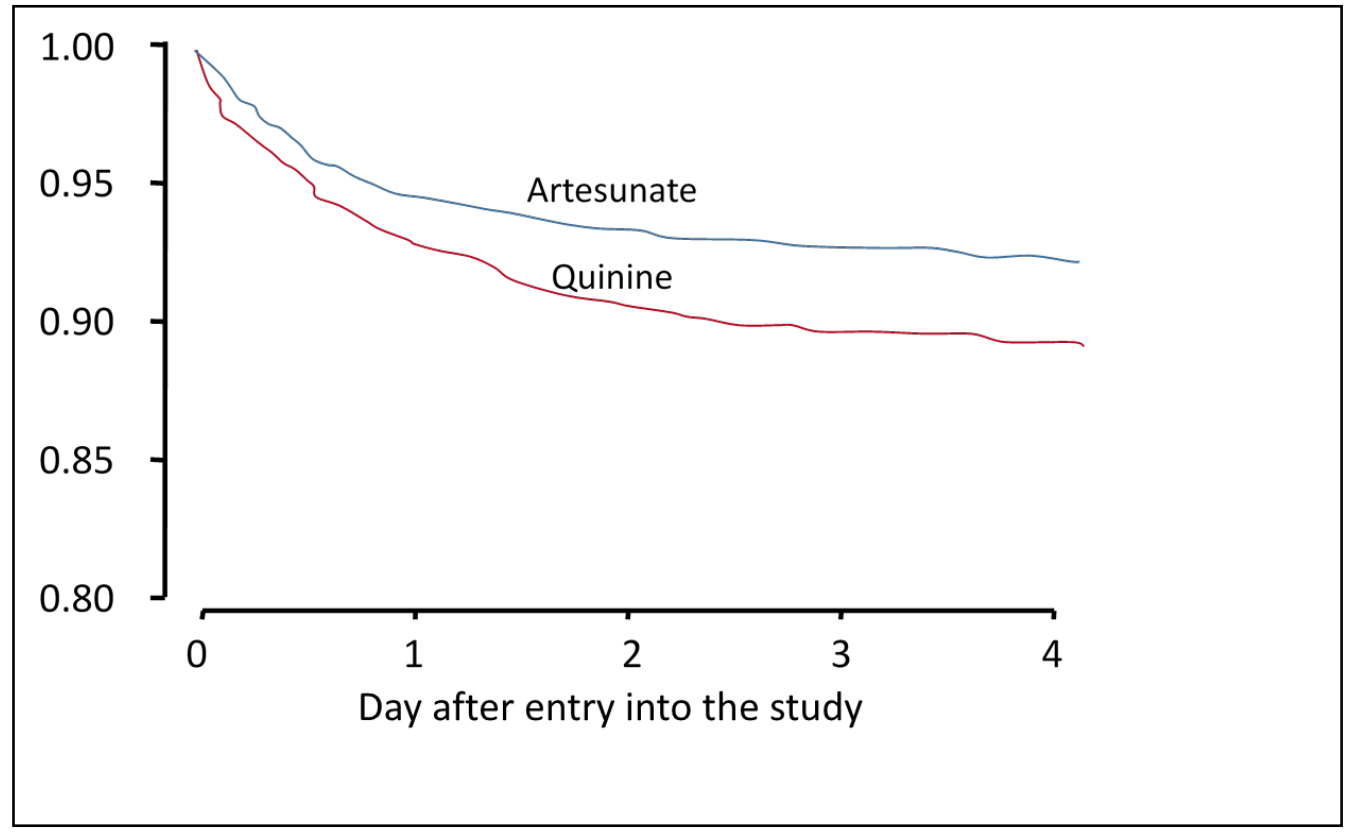

Figure 2 Reduced mortality from severe malaria after artesunate treatment compared to quinine.

Table footnote: Between 2005 and 2010 the AQUAMAT study enrolled 5425 children in nine African countries with severe malaria. There was a relative mortality reduction of $22.5 \%$ (95\% Cl 8.1-36.9; $\mathrm{p}=0.0022)$ in artesunate-treated compared to quinine-treated children. ${ }^{134}$

Y axis legend: Mortality proportion 

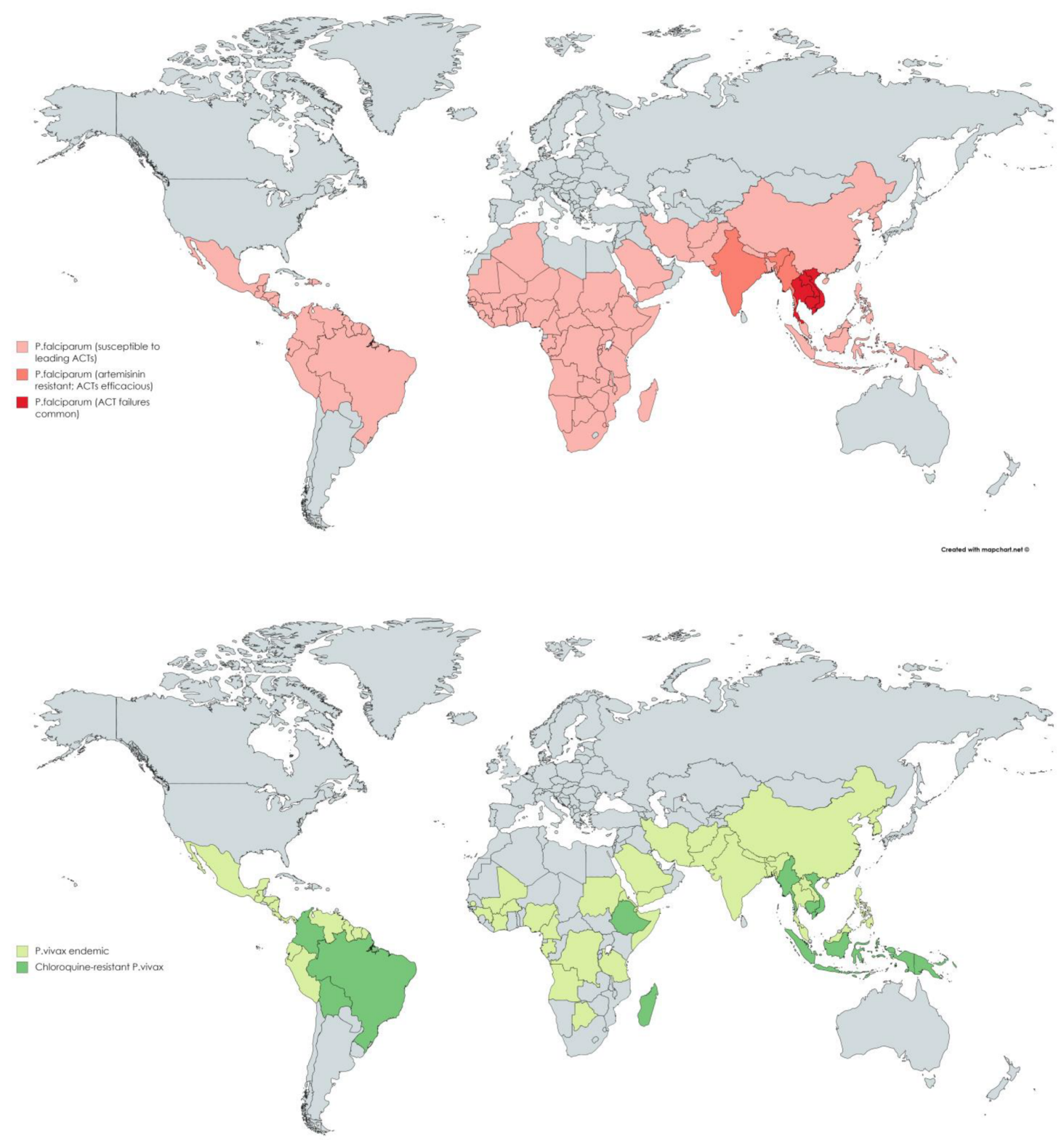

Figure 3 Maps of distribution of drug-resistant malaria caused by Plasmodium falciparum (A) and Plasmodium vivax (B).

Footnote: Countries are depicted as having evidence of chloroquine resistant $P$.vivax if trials have shown $>10 \%$ recurrence by day 28 (with a lower $95 \% \mathrm{Cl}$ of $>5 \%$ ), irrespective of confirmation of adequate blood chloroquine concentration. ${ }^{34}$ 
Table 1. Malaria Treatment in Children

\begin{tabular}{|c|c|c|}
\hline Species \& presentation & Antimalarial drug options & Comments \\
\hline \multirow[t]{3}{*}{$\begin{array}{l}\text { Uncomplicated } P \text {. falciparum } \\
\text { and } P \text {. vivax (areas with high } \\
\text { grade chloroquine resistant } P \text {. } \\
\text { vivax infections) }\end{array}$} & $\begin{array}{l}\text { Dihydroartemisinin }+ \\
\text { piperaquine (DHA-Pip) } \\
\text { Formulation: FDC } 20 \mathrm{mg}+160 \\
\mathrm{mg} \text { (paediatric) and } 40 \\
\mathrm{mg}+320 \mathrm{mg} \\
\text { Dosage [target dose (range)]: } \\
\text { once daily for } 3 \text { days } \\
\text { - BW } 25 \mathrm{~kg}: 4 \text { ( } 2-10) \mathrm{mg} / \mathrm{kg} \\
\quad \text { bw of DHA and } 18 \text { (16-27) } \\
\mathrm{mg} / \mathrm{kg} \mathrm{bw} \text { of Pip } \\
\text { BW<25 kg: minimum dose } \\
2.5 \mathrm{mg} / \mathrm{kg} \text { bw of DHA and } \\
20 \mathrm{mg} / \mathrm{kg} \text { bw of Pip. } \\
\text { BW } \leq 5 \mathrm{~kg} \text { : give similar } \\
\text { dose as for } 5 \text { kg infants. }\end{array}$ & $\begin{array}{l}\text { Preferred option in endemic } \\
\text { areas without evidence of } \\
\text { piperaquine resistance: } \\
\text { - Consistent high efficacy } \\
\text { profile against } P \text {. } \\
\text { falciparum and } P \text {. vivax } \\
\text { malaria }{ }^{135} \\
\text { - Compared to AL: better } \\
\text { post treatment } \\
\text { prophylactic effect in } P \text {. } \\
\text { vivax infections }{ }^{46} \\
\text { Dose adjustment has been } \\
\text { defined in children }{ }^{53} \\
\text { Dispersible tablet was } \\
\text { similarly effective } \\
\text { compared to crushed } \\
\text { tablet in a phase II trial }{ }^{136} \\
\end{array}$ \\
\hline & $\begin{array}{l}\text { Artesunate + mefloquine } \\
\text { (AMQ) } \\
\text { Formulation: FDC } 25 \text { mg+55 } \\
\text { mg mefloquine hydrochloride } \\
\text { (paediatric), } 100 \mathrm{mg}+220 \\
\text { mefloquine hydrochloride } \\
\text { Dosage [target dose (range)]: } \\
\text { once daily for } 3 \text { days } \\
\text { - } \quad 4(2-10) \mathrm{mg} / \mathrm{kg} \text { bw of } \\
\quad \text { artesunate and } 8.3 \text { (7-11) } \\
\mathrm{mg} / \mathrm{kg} \text { of mefloquine }\end{array}$ & $\begin{array}{l}\text { Preferred option in endemic } \\
\text { areas without evidence of } \\
\text { mefloquine resistance: } \\
\text { - Similarly effective with AL } \\
\text { for } P \text {. falciparum malaria in } \\
\text { children under-five in } \\
\text { Africa; }{ }^{137} \text { or DHA-Pip in } \\
\text { Asia }{ }^{135} \\
\text { - Comparable efficacy with } \\
\text { DHA-Pip against recurrent } \\
\text { P. vivax malaria }{ }^{39} \\
\text { - No dose adjustment in } \\
\text { children is required }\end{array}$ \\
\hline & $\begin{array}{l}\text { Artemether + lumefantrine } \\
\frac{\text { (AL) }}{\text { Formulation: FDC } 20} \\
\mathrm{mg}+120 \mathrm{mg} \text { (paediatric) and } 40 \\
\mathrm{mg}+240 \mathrm{mg} \\
\text { Dosage (total dose): twice } \\
\text { daily for } 3 \text { days } \\
\begin{array}{l}\text { - } \quad 5-24 \mathrm{mg} / \mathrm{kg} \text { bw of } \\
\text { artemether and } 29-144 \\
\mathrm{mg} / \mathrm{kg} \text { bw of lumefantrine }\end{array}\end{array}$ & $\begin{array}{l}\text { Alternative option for } P \text {. } \\
\text { falciparum malaria: } \\
\text { - Similar efficacy profile with } \\
\text { DHA-Pip against } P \text {. } \\
\text { falciparum infections }{ }^{135} \\
\text { - Dose adjustment in } \\
\text { children aged }<3 \text { years old } \\
\text { may be required }{ }^{54} \\
\text { - Twice daily dose might } \\
\text { affect treatment } \\
\text { adherence in young } \\
\text { children }\end{array}$ \\
\hline
\end{tabular}




\begin{tabular}{|c|c|c|}
\hline & & 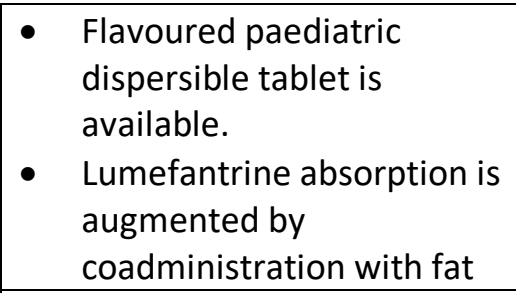 \\
\hline & $\begin{array}{l}\frac{\text { Artesunate + amodiaquine }}{\text { (AAQ) }} \\
\text { Formulation: FDC } 25 \\
\mathrm{mg}+67.5 \mathrm{mg}, 50 \mathrm{mg}+135 \mathrm{mg} \text {, } \\
100 \mathrm{mg}+270 \mathrm{mg} \\
\text { Dosage [target dose (range)]: } \\
\text { once daily for } 3 \text { days } \\
\text { - } 4(2-10) \mathrm{mg} / \mathrm{kg} \text { bw of } \\
\text { artesunate, and } 10 \text { (7.5- } \\
\text { 15) } \mathrm{mg} / \mathrm{kg} \text { bw of } \\
\text { amodiaquine } \\
\text { BW } \leq 50 \mathrm{~kg}: \text { amodiaquine } \\
\text { dose range } 11-19.8 \mathrm{mg} / \mathrm{kg} \\
\text { bw }\end{array}$ & $\begin{array}{l}\text { Option for } P \text {. falciparum } \\
\text { infections treatment in Africa: } \\
\text { - Africa: similar efficacy } \\
\text { profile with DHA-Pip } \\
\text { against } P \text {. falciparum } \\
\text { malaria in children }{ }^{138} \\
\text { - Asia-Pacific: lower efficacy } \\
\text { profile compared to DHA- } \\
\text { Pip against } P \text {. falciparum } \\
\text { and } P \text {. vivax malaria }{ }^{39} \\
\text { Dose adjustment in } \\
\text { patients weighing } \leq 50 \mathrm{~kg} \text { is } \\
\text { recommended }{ }^{57}\end{array}$ \\
\hline & $\begin{array}{l}\text { Artesunate + sulfadoxine- } \\
\text { pyrimethamine (ASP): } \\
\text { Formulation: } 50 \text { mg artesunate } \\
\text { and FDC 500mg sulfadoxine } \\
\text { +25 mg pyrimethamine (SP) } \\
\text { Dosage [target dose (range)]: } \\
\text { Once daily artesunate for } 3 \\
\text { days and single dose SP } \\
\text { - } \quad 4 \text { (2-10) mg/kg bw of } \\
\text { artesunate. } \\
\text { SP number of tablets (500 } \\
\text { mg/ } 25 \text { mg) according to } \\
\text { BW: <8 kg: } 0.5 \text { tab; } 8-13 \\
\quad \text { kg: } 1 \text { tab; } 14-24 \mathrm{~kg}: 1.5 \\
\text { tab; } 25-38 \mathrm{~kg}: 2 \text { tab, } 39-49 \\
\text { kg: } 2.5 \text { tab; } 50-68 \mathrm{~kg}: 3 \text { tab, } \\
\geq 69 \mathrm{~kg}: 4 \text { tab. }\end{array}$ & $\begin{array}{l}\text { Least recommended ACT: } \\
\text { - } \quad \text { Lower efficacy against } P \text {. } \\
\text { falciparum malaria } \\
\text { compared to AL }{ }^{139} \\
\text { - } \quad \text { Lower efficacy against } P \text {. } \\
\text { vivax compared to DHA-Pip } \\
39,135 \\
\text { - } \quad \text { Dose adjustment in } \\
\text { children older than } 1 \text { year } \\
\text { old is recommended }{ }^{56}\end{array}$ \\
\hline $\begin{array}{l}\text { Uncomplicated } P \text {. vivax (area } \\
\text { with chloroquine sensitive } P \text {. } \\
\text { vivax infections) }\end{array}$ & $\begin{array}{l}\text { Chloroquine } \\
\text { Dosage: } 10 \mathrm{mg} \text { base/kg bw day } \\
1 \text { and } 2,5 \mathrm{mg} \text { base/kg bw day } \\
\text { 3. Children: total dose } 30 \\
\mathrm{mg} / \mathrm{kg} \mathrm{BW} \text { over } 3 \text { days. }\end{array}$ & $\begin{array}{ll}\text { - } & \text { More effective with an } \\
\text { increased dose }{ }^{60} \\
\text { - } & \text { Required a skilled } \\
\text { microscopist to } \\
\text { differentiate species. If in } \\
\text { doubt, treat with ACTs. }\end{array}$ \\
\hline $\begin{array}{l}\text { Uncomplicated } P \text {. malariae, } P \text {. } \\
\text { ovale and } P \text {. knowlesi }\end{array}$ & $\begin{array}{l}\text { As for uncomplicated } P \text {. } \\
\text { falciparum and } P \text {. vivax } \\
\text { malaria treatment }\end{array}$ & $\begin{array}{l}\text { - Limited evidence is } \\
\text { available on the efficacy } \\
\text { profile of ACTs in children } \\
39\end{array}$ \\
\hline
\end{tabular}




\begin{tabular}{|c|c|c|}
\hline & & $\begin{array}{l}\text { - ACTs preferred for } \\
\text { P.knowlesi }{ }^{33}\end{array}$ \\
\hline $\begin{array}{l}\text { Children aged } \geq 6 \text { months with } \\
P \text {. vivax and } P \text {. ovale infections }\end{array}$ & $\begin{array}{l}\text { Anti-relapse treatment } \\
\text { (hypnozoitocidal agents): } \\
\text { Primaquine } 0.25-0.5 \mathrm{mg} / \mathrm{kg} \text { bw } \\
\text { for } 14 \text { days (maximum dose } 30 \\
\text { mg daily) }\end{array}$ & $\begin{array}{l}\text { Co-administration with } \\
\text { chloroquine and ACTs } \\
\text { provide lower risk of } \\
\text { relapses/recurrences. }{ }^{46,60} \\
\text { - Should be given to G6PD } \\
\text { normal individuals; if G6PD } \\
\text { test is not available, } \\
\text { consider the risk and } \\
\text { benefit of adding } \\
\text { primaquine }\end{array}$ \\
\hline $\begin{array}{l}\text { Children aged } \geq 6 \text { months with } \\
P . \text { falciparum infections }\end{array}$ & $\begin{array}{l}\text { Anti-gametocyte treatment: } \\
\text { Primaquine } 0.25 \mathrm{mg} / \mathrm{kg} \text { bw } \\
\text { single dose (maximum dose } 15 \\
\mathrm{mg} \text { ) }\end{array}$ & $\begin{array}{l}\text { - } \text { Co-administration with } \\
\text { ACTs. }{ }^{140} \\
\text { - } \text { G6PD testing is not } \\
\text { required }{ }^{32}\end{array}$ \\
\hline $\begin{array}{l}\text { Severe malaria caused by any } \\
\text { Plasmodium species }\end{array}$ & 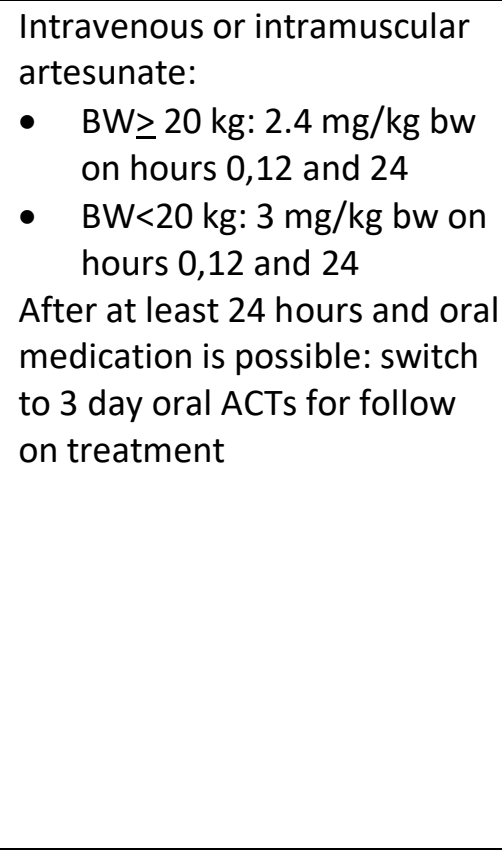 & $\begin{array}{l}\text { Preferred option for any severe } \\
\text { malaria: } \\
\text { - Highly effective for the } \\
\text { treatment of severe } P \text {. } \\
\text { falciparum malaria in } \\
\text { children. }{ }^{134} \\
\text { - Its use in severe non- } \\
\text { falciparum malaria is highly } \\
\text { recommended to prevent } \\
\text { mortality. }{ }^{32} \\
\text { Avoid mefloquine } \\
\text { containing ACTs because of } \\
\text { increased risk of post- } \\
\text { malaria neurological } \\
\text { syndrome }{ }^{141} \\
\text { If parenteral artesunate is } \\
\text { not available, quinine can } \\
\text { be used as an alternative. }\end{array}$ \\
\hline $\begin{array}{l}\text { Congenital malaria } \\
\text { Severe falciparum and vivax } \\
\text { infections }\end{array}$ & $\begin{array}{l}\text { Intravenous or intramuscular } \\
\text { artesunate dose as for } \mathrm{BW}<20 \\
\text { kg at least the first dose and } \\
\text { continue with follow on } 3 \text { day } \\
\text { oral ACTs. }\end{array}$ & $\begin{array}{l}\text { Congenital malaria is defined } \\
\text { as peripheral parasitaemia } \\
\text { found in the first } 28 \text { days of life } \\
\text { (cross ref companion Saito } \\
\text { paper) }\end{array}$ \\
\hline $\begin{array}{l}\text { Uncomplicated vivax and } \\
\text { ovale malaria }\end{array}$ & $\begin{array}{l}\text { Follow treatment options } \\
\text { according to } P \text {. vivax sensitivity } \\
\text { to chloroquine. }\end{array}$ & $\begin{array}{l}\text { Radical cure is not indicated as } \\
\text { blood stage infections occur } \\
\text { directly from the mother; thus } \\
\text { there are no dormant } \\
\text { hypnozoites in the liver. }\end{array}$ \\
\hline
\end{tabular}

Notes: FDC: fixed dose combination; BW/bw: body weight. Recommendations are in line with the $3^{\text {rd }}$ edition of the WHO Malaria Treatment Guidelines ${ }^{32}$ 
Table 2 Important drug-drug interactions with antimalarials

\begin{tabular}{|c|c|c|}
\hline Antimalarial & Other drug(s) & Description of interaction \\
\hline Amodiaquine & $\begin{array}{l}\text { Efavirenz } \\
\text { Zidovudine }\end{array}$ & $\begin{array}{ll}\text { - } & \text { Hepatotoxicity }{ }^{142} \\
\text { - } & \text { Neutropenia }\end{array}$ \\
\hline Artemether-lumefantrine & $\begin{array}{l}\text { Rifampicin } \\
\text { Efavirenz } \\
\text { Nevirapine } \\
\text { Lopinavir-ritonavir } \\
\text { Darunavir-ritonavir } \\
\text { Etravirine } \\
\text { Mefloquine }\end{array}$ & $\begin{array}{l}\text { - Rifampicin decreases lumefantrine (and } \\
\text { artemether) exposure (CYP3A4 induction). } \\
\text { Efavirenz and nevirapine reduce } \\
\text { artemether, and dihydroartemisinin } \\
\text { exposure. }{ }^{143-145} \\
\text { - } \text { Lopinavir-ritonavir and darunavir-ritonavir } \\
\text { increase lumefantrine exposure. }{ }^{146,147} \\
\text { Etravirine reduces artemether, DHA and } \\
\text { lumefantrine exposure. }{ }^{147} \text { Concomitant } \\
\text { mefloquine results in lower lumefantrine } \\
\text { concentrations. }{ }^{148}\end{array}$ \\
\hline Atovaquone-proguanil & $\begin{array}{l}\text { Efavirenz } \\
\text { Lopinavir/ritonavir } \\
\text { Atazanavir/ritonavir }\end{array}$ & Atovaquone exposure is reduced ${ }^{149}$ \\
\hline $\begin{array}{l}\text { Dihydroartemisinin- } \\
\text { piperaquine }\end{array}$ & Efavirenz & Decreased piperaquine exposure \\
\hline Primaquine & $\begin{array}{l}\text { Chloroquine } \\
\text { DHA-piperaquine } \\
\text { Artesunate } \\
\text { pyronaridine }\end{array}$ & $\begin{array}{l}\text { Coadministration increases primaquine } \\
\text { exposure. }{ }^{150-152}\end{array}$ \\
\hline Quinine & Rifampicin & $\begin{array}{l}\text { Rifampicin increases metabolic clearance of } \\
\text { quinine }\end{array}$ \\
\hline Sulfadoxine-pyrimethamine & $\begin{array}{l}\text { Other antifols e.g. } \\
\text { trimethoprim }\end{array}$ & Increased risk of toxicity \\
\hline
\end{tabular}


Table 3 Molecular markers associated with antimalarial drug resistance

\begin{tabular}{|c|c|c|c|}
\hline Antimalarial & $\begin{array}{l}\text { Resistance } \\
\text { marker }\end{array}$ & Notes & $\begin{array}{l}\text { Geographical } \\
\text { distribution }\end{array}$ \\
\hline Amodiaquine & $\begin{array}{l}\text { pfcrt } \\
\text { pfmdr1 }\end{array}$ & $\begin{array}{l}\text { SVMNT haplotype } \\
\text { including } \\
\text { K76T } \\
\text { N86Y }\end{array}$ & $\begin{array}{l}\text { East Africa, Southeast } \\
\text { Asia }\end{array}$ \\
\hline Artemisinin & kelch13 & $\begin{array}{l}\text { Single mutations - } \\
\text { F446I, P553L, N458Y, } \\
\text { R561H, M476I, Y493H, } \\
\text { R539T, I543T } \\
\text { C580Y dominates in areas } \\
\text { of high level resistance }\end{array}$ & $\begin{array}{l}\text { Southeast (C580Y) and } \\
\text { South Asia, Guyana, } \\
\text { Rwanda }\end{array}$ \\
\hline Atovaquone & CytB & $\mathrm{Y} 268 \mathrm{~S} / \mathrm{C} / \mathrm{N}$ & $\begin{array}{l}\text { Cambodia (emerged } \\
\text { rapidly after } \\
\text { deployment of } \\
\text { atovaquone-proguanil } \\
\text { in 2014) }\end{array}$ \\
\hline Chloroquine & $\begin{array}{l}\text { pfcrt } \\
\text { pfmdr1 } \\
\text { pvcrt-0 } \\
\text { pvmdr-1 }\end{array}$ & $\begin{array}{l}\text { 'CVIET' haplotype } \\
\text { including K76T } \\
\text { N86Y (augments } \\
\text { resistance) } \\
\end{array}$ & Worldwide \\
\hline Lumefantrine & pfmdr1 & $\begin{array}{l}\text { Gene amplification } \\
\text { (associated with low } \\
\text { grade resistance in } \\
\text { Southeast Asia). Selection } \\
\text { of pfmdr1 } \\
86 \mathrm{~N} \text { allele after treatment } \\
\text { observed in Africa }\end{array}$ & $\begin{array}{l}\text { High failure rates of } \\
\text { artemether- } \\
\text { lumefantrine } \\
\text { documented in } \\
\text { Cambodia (2000-2005). }\end{array}$ \\
\hline Mefloquine & $p f m d r 1$ & Gene amplification & Thailand, Myanmar \\
\hline Piperaquine & plasmepsin2 & Gene amplification & $\begin{array}{l}\text { Cambodia, Thailand, } \\
\text { Laos, Vietnam. Recently } \\
\text { described in Africa }^{153}\end{array}$ \\
\hline
\end{tabular}




\begin{tabular}{|c|l|l|l|}
\hline Pyrimethamine & $\begin{array}{l}\text { dhfr } \\
\text { pfgch1 }\end{array}$ & $\begin{array}{l}\text { N51I, C59R, S108N, I164L } \\
\text { Gene amplification }\end{array}$ & Worldwide $^{\mathrm{a}}$ \\
\hline Sulfadoxine & dhps & $\begin{array}{l}\text { S436A/F, A437G, K540E, } \\
\text { A581G, A613S/T }\end{array}$ & Worldwide $^{\mathrm{a}}$ \\
\hline
\end{tabular}

${ }^{\text {aThe }}$ pfdhfr N51I/C59R/S108N/pfdhps A437G/K540E quintuple mutant is associated with high grade SPresistance

Table 4 Recommendations for Malaria Treatment and Prevention in Children 
National malaria control programmes

- All sick children should have immediate access to early diagnosis and prompt effective treatment:

- Microscopy or Rapid Diagnostic Tests (RDT)

- ACTs for uncomplicated malaria

- Parenteral artesunate for severe malaria

- Radical cure for $P$. vivax malaria with primaquine in G6PD normal children (if G6PD status unknown, consider the risks and benefits of treatment with close monitoring of urine colour in the first 3 days for signs of acute hemolysis-dark urine)

- Drug resistance monitoring and surveillance should be carried out regularly

- Unified treatment policy with ACTs could be considered in ACT sensitive areas

- Uptake of $P$. falciparum malaria chemoprevention in SP/amodiaquine sensitive areas in Africa should be increased:

- Infants (1-12 months): IPTi with SP

$\circ$ Children $<5$ years: SMC with SP+amodiaquine

- DHA-Pip could be used as alternative for IPTi and SMC in areas of high grade SP resistance

- IPT for school aged children (>5-12 years) using DHA-Pip could be considered

- All children living in high malaria transmission areas should sleep under Insecticide Treated Nets

\section{Research}

Treatment:

- Develop new safe and effective agents for radical cure of children infected with P.vivax

- Develop a primaquine treatment adherence and safety package for health workers and the community in resource limited settings, including point of care G6PD testing

- Evaluate the safety and efficacy of triple antimalarial combinations for deployment in areas of drug-resistant malaria

- Develop new antimalarials for treatment and evaluate in children earlier in development process

Prevention:

- More research to define optimum agents for prevention and dosing strategies, and long term impacts e.g.

- Evaluate the efficacy and effectiveness of IPTi and SMC using DHA-Pip for $P$. falciparum and $P$. vivax malaria prevention in infants, under-five years old and school aged children

- Evaluate the efficacy and effectiveness of SMC expanded to other age groups

- Develop new antimalarials for prevention

Health Systems:

- Study linkage with national EPI or other national campaigns to increase IPTi uptake

- Strengthen integrated community case management with other causes of childhood illness 